\title{
An open workflow for the study of unseen weather extremes
}

T. Kelder ${ }^{1}$, T.I. Marjoribanks ${ }^{2}$, L.J. Slater ${ }^{3}$, C. Prudhomme ${ }^{1,4,5}$, R.L. Wilby ${ }^{1}$ J. Wagemann $^{4}$, N. Dunstone ${ }^{6}$

${ }^{1}$ Geography and Environment, Loughborough University, Loughborough, UK

${ }^{2}$ School of Architecture, Building and Civil Engineering, Loughborough, UK

${ }^{3}$ School of Geography and the Environment, University of Oxford, Oxford, UK

${ }^{4}$ European Centre for Medium-Range Weather Forecasts (ECMWF), Reading, UK

${ }^{5}$ UK Centre for Ecology and Hydrology, Wallingford, UK

${ }^{6}$ Met Office Hadley Centre, Exeter, UK

Correspondence to: T. Kelder (t.kelder@lboro.ac.uk)

Twitter handle: @ TimoKelder 


\begin{abstract}
Ensemble members from weather and climate predictions can be used to generate large samples of simulated weather events, allowing the estimation of extreme (hitherto unseen) events. Here, we provide a protocol and open workflow for applying the 'UNSEEN' method for hydro-climatic extremes globally, based on Copernicus Climate Change Services (C3S) seasonal predictions but also considering other compatible modelling systems. We discuss common challenges and potential solutions using three examples of extreme events that caused severe damage in 2020 (extreme rainfall, heat, and wildfire danger). These case studies demonstrate the potential of the method to inform decision-making with maximum credible events used for stress-testing adaptation measures and to anticipate unprecedented extremes in a changing climate. As such, this paper may be used to guide the generation of large ensembles that are a credible resource for evaluating otherwise unforeseen hydro-climatic risks.
\end{abstract}

\title{
Keywords
}

Hydro-climatic extremes; climate change; climate risk; climate model ensemble; Copernicus Climate Change Services; seasonal predictions

\section{Introduction}

Understanding the likelihood, trends, and driving processes of extreme hydro-meteorological events is crucial for decision making (Salas et al., 2018; Slater et al., 2021). However, it is challenging to compute robust statistics for rare events from short historical records, especially in data scarce regions. Instrumental records are typically only a few decades long and are not available everywhere (e.g. Alexander, 2016). Reanalysis products are increasingly employed to estimate extremes, as they blend observational datasets with model simulations into spatially and temporally coherent outputs, i.e., 'maps without gaps' (e.g. ECMWF, 2018). For example, the European Centre for Medium-Range Weather Forecasts (ECMWF) ERA5 reanalysis (Hersbach et al., 2020) has been used to estimate rainfall intensity-duration-frequency (IDF) curves globally (Courty et al., 2019), trends in extremes (Faranda, 2020; Geirinhas et al., 2021; Kim et al., 2021), driving processes behind extreme events (Grazzini et al., 2020), and extreme weather indices (Kennedy-Asser et al., 2021; Wehner et al., 2020). Although reanalyses overcome spatial data scarcity, they can exhibit model deficiencies or inhomogeneities (Parker, 2016), and their typical length ( 70years) may still be a limiting factor when studying extreme events. 
BOX A. The UNprecedented Simulated Extremes using ENsembles (UNSEEN) approach

By treating model ensemble members as different, but equally plausible versions of the past, then pooling them, the sample size of historical weather events can be increased to explore the characteristics of rare extreme events (van den Brink et al., 2005). So far, this approach has helped estimate the likelihood of floods (e.g. Brunner and Slater, 2021; Thompson et al., 2017; van den Brink et al., 2004), droughts (Kent et al., 2019, 2017; Pascale et al., 2020), wind losses (Osinski et al., 2016; Walz and Leckebusch, 2019), and heatwaves (Cowan et al., 2020; Kay et al., 2020; Thompson et al., 2019). Furthermore, the approach has been used to evaluate compound hazards (Hillier and Dixon, 2020) and to detect trends in rare extreme events over past decades (Diffenbaugh et al., 2017; Kay et al., 2020; Kelder et al., 2020; Kirchmeier-Young and Zhang, 2020) and in future projections (e.g. King et al., 2017; Lehner et al., 2017; Suarez-Gutierrez et al., 2020; Swain et al., 2020). Ensemble members from prediction systems have been used across timescales, ranging from weeks (Breivik et al., 2014, 2013; Meucci et al., 2018; Osinski et al., 2016), through months (Hillier and Dixon, 2020; Jain et al., 2020; Kelder et al., 2020; van den Brink et al., 2005, 2004; Walz and Leckebusch, 2019), years (Cowan et al., 2020; Dunstone et al., 2016; Guillod et al., 2017; Kay et al., 2020; Kent et al., 2019, 2017; Thompson et al., 2019, 2017; van der Wiel et al., 2020, 2019; van Kempen et al., 2021), and decades (Mitchell et al., 2017; Poschlod et al., 2021) to centuries (Bhatia and Ganguly, 2019; King et al., 2017; Lehner et al., 2017; Stevenson et al., 2015; Swain et al., 2020; van der Wiel et al., 2018). The use of hindcast ensembles to assess present-climate risks arising from weather extreme events is known as the UNprecedented Simulated Extremes using ENsembles (UNSEEN) approach (Thompson et al., 2017).

Ensemble retrospective predictions (hindcasts) from weather and climate models offer an alternative to observational records, weather generators, or reanalyses for the study of past hydro-climatic events (BOX A). Hindcast ensembles have considerable potential to improve present-climate risk estimates, including engineering design standards (e.g. Jain et al., 2020; Thompson et al., 2017), detecting and explaining trends in rare extremes (e.g. Kelder et al., 2020), or understanding the dynamics of unprecedented events (e.g. Kay et al., 2020). Furthermore, event-based storylines may help to identify plausible - yet unseen - weather extremes to reveal present-climate risks and impacts (Matthews et al., 2016; Sillmann et al., 2021). Interdisciplinary efforts may use such storylines to assess threats such as heat-related mortality (e.g. Gasparrini et al., 2015), economic damages (Klomp and Valckx, 2014), and livelihood impacts (Bauer et al., 2018). However, there are still questions around 
the applicability of the method (BOX B), such as whether hindcast ensembles can provide credible, multiple 'maps without gaps'.

This paper presents a protocol to guide users when generating large samples of weather events from hindcast ensembles to evaluate extremes (Figure 1). The procedure begins by selecting the type of hydro-meteorological event of interest with requisite spatial and temporal scales (step 1). The type of event being studied informs the selection of the most appropriate prediction system (step 2). We then discuss how data can be retrieved (step 3) and pre-processed (step 4) before being evaluated (step 5). For events with poor applicability (BOX B), possible solutions are discussed (step 6). A technical workflow (UNSEEN-open, documented at https://unseenopen.readthedocs.io) was developed for steps 3-5 during the ECMWF Summer of Weather Code 2020 (https://esowc.ecmwf.int/). This workflow facilitates the process of retrieving, pre-processing and evaluating the latest ECMWF seasonal prediction system 5 (SEAS5, Johnson et al., 2019) but could be adapted for other modelling systems.

Following sections step through the protocol, illustrated by three worked examples of extreme events that occurred in 2020. During February, the UK endured floods that caused more than $£ 300$ million in damage and destroyed 3400 houses (Copernicus EMS, 2020). Later that year, prolonged heat over Siberia caused wildfires, invasion of pests and infrastructure failure, as well as global impacts through the release of greenhouse gasses from thawing permafrost (Ciavarella et al., 2021; Overland and Wang, 2021). Meanwhile, wildfires in California contributed to the (then) worst fire season on record (Pickrell and Pennisi, 2020), amplifying hardships faced by communities during the COVID-19 pandemic (Moore et al., 2020). Section 2 describes the six steps of the protocol. Section 3 provides an overview for each of the three case studies. In section 4, we discuss the practicalities of the UNSEENopen workflow, with further evaluation and adjustment of methods, plus reference to other applicable data sets. Section 5 concludes the paper with final remarks. 
BOX B. Three challenges associated with generating an UNSEEN ensemble.

The applicability of hindcast ensembles for generating large samples of weather events hinges on three common challenges faced by all prediction systems: the independence of the ensemble members, the stability of the model, and the fidelity of the simulations (Kelder et al., 2020; Thompson et al., 2019, 2017).

Independence: Ensemble member independence (i.e., the uniqueness of each model ensemble member) is closely linked to the spread and predictability of forecasts. When a forecast is initialised, the ensemble member independence is low because the ensemble members only differ slightly in their initial conditions. The spread of the individual ensemble members increases over the forecasting horizon because they develop their own 'virtual world' induced by stochastic processes in the atmosphere. The importance of ensemble member independence can be best explained through an example of extreme value analysis. Dam safety standards requires preparedness for very unlikely scenarios, such as the 10,000-year inflow return value. Large ensemble hindcasts might be used to generate an UNSEEN ensemble that can capture such events. However, if the UNSEEN ensemble members are correlated, one might think that 10,000 years were simulated adequately, whereas the effective ensemble size is in practice much smaller.

Stability: Ensemble members may drift away from their initial climatology (near to an observed state) towards a steady virtual climatology (Covey et al., 2006; Gupta et al., 2013, 2009; Hermanson et al., 2018). Such drifts are not caused by external forcing or internal low frequency variability but by numerical errors (e.g. Liepert and Previdi, 2012; Lucarini and Ragone, 2011), model imbalances and/or discontinuities (e.g. Rahmstorf, 1995). Drift is mostly present in physical ocean variables, but can be evident in atmospheric properties (Gupta et al., 2013). Hence, model instability (i.e., the presence of drift) may deteriorate the realism of the hindcast ensemble.

Fidelity: Model simulations are virtual representations of reality, and 'fidelity' refers to their ability to realistically simulate the target event(s). Hence, for robust analyses using climate model simulations, their 'virtual world' must realistically describe 'reality', i.e., the extreme event being studied. Systematic errors such as in cloud microphysics, tropical cyclones, convective precipitation, teleconnections and synoptic regimes in numerical prediction systems may bias the simulation of extreme events (e.g. Zadra et al., 2018). Processes that occur on scales smaller than the model grid cannot be resolved but must be parameterized, leading to lower fidelity (Sillmann et al., 2017). Furthermore, mechanisms such as self-intensification of droughts via land-atmosphere feedbacks, are currently not well-represented by climate models (Miralles et al., 2019). Therefore, an evaluation of model fidelity is crucial. 


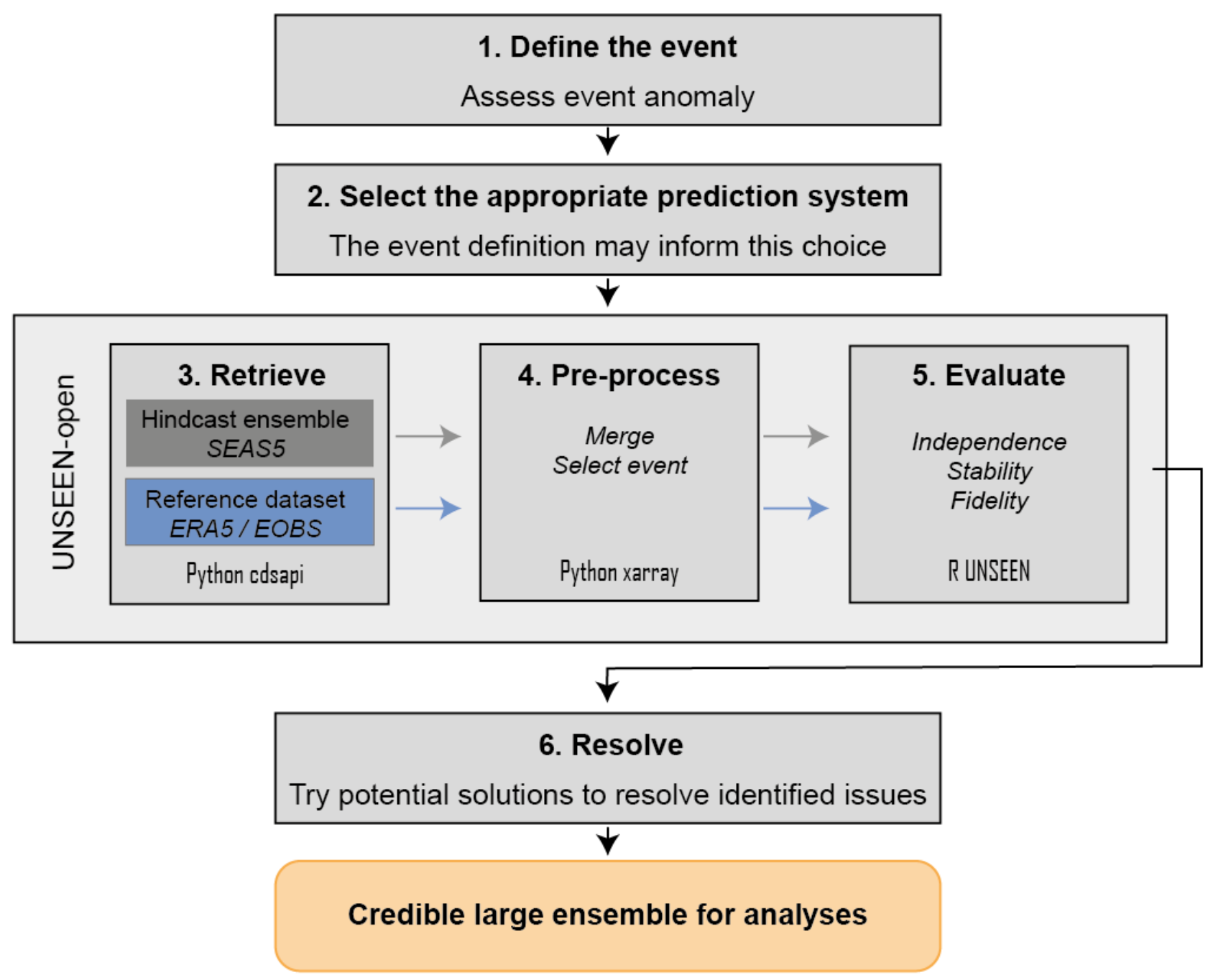

Figure 1. Protocol for generating a credible large ensemble of weather events. Grey boxes indicate the six steps of the protocol. The larger light grey box surrounding steps 3-5 shows the UNSEEN-open workflow, documented at https://unseen-open.readthedocs.io. For these steps, the programming language and package are indicated. The orange box indicates the outcome of a credible large ensemble that can be used for extreme event analyses. 


\section{The protocol}

\section{Step 1: Define the event}

To apply the UNSEEN method, a hydro-meteorological event is first defined. The event definition depends on the scope of the analysis in terms of the target domain, timescale, and (meteorological) variable of interest. Any domain, timescale and variable can be selected, e.g., to estimate design values or to quantify the likelihood of unprecedented events. In the examples below, events were defined to best represent the footprint of historical hydro-meteorological incidents. For some cases, the definition is straightforward, such as for studying UK-average extreme precipitation in February (section 3.3). In other cases, such as for the Siberian heatwave (Figure 2a,c and section 3.1) and temperature anomalies during peak California wildfire activity (Figure 2b,d and section 3.2), the domain and timescale may be informed by an assessment of the event anomaly ${ }^{1}$ or the region where historical records were broken ${ }^{2}$. Detailed protocols for defining the extent, timescale, and meteorological variable representative of target events can be found in Philip et al. (2020) and van Oldenborgh et al. (2021).

\footnotetext{
${ }^{1}$ See $\mathrm{https}$ ://unseen-open.readthedocs.io/en/latest/Notebooks/California_august_temperature_anomaly.html

${ }^{2}$ See https://unseen-open.readthedocs.io/en/latest/Notebooks/Global_monthly_temperature records_ERA5.html
} 
a

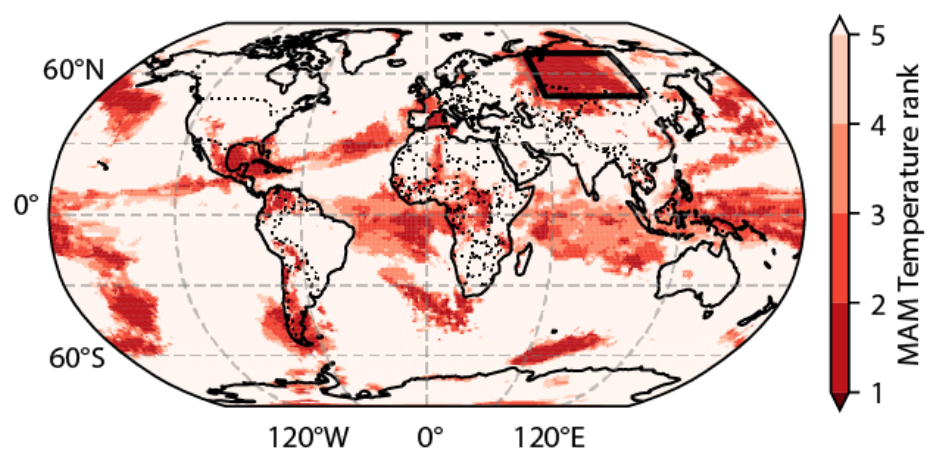

b

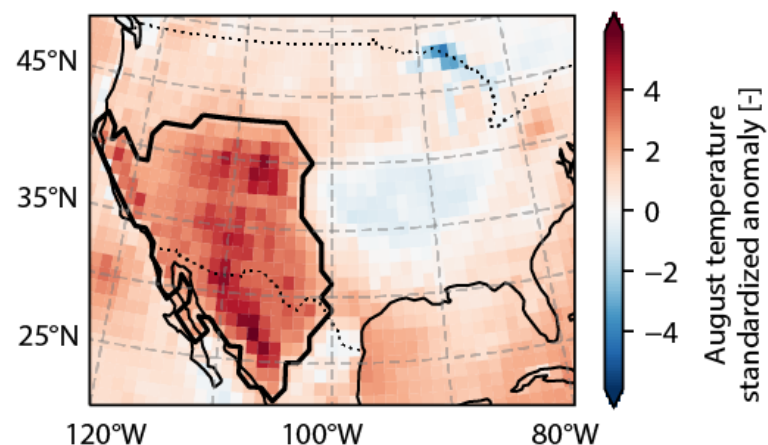

d

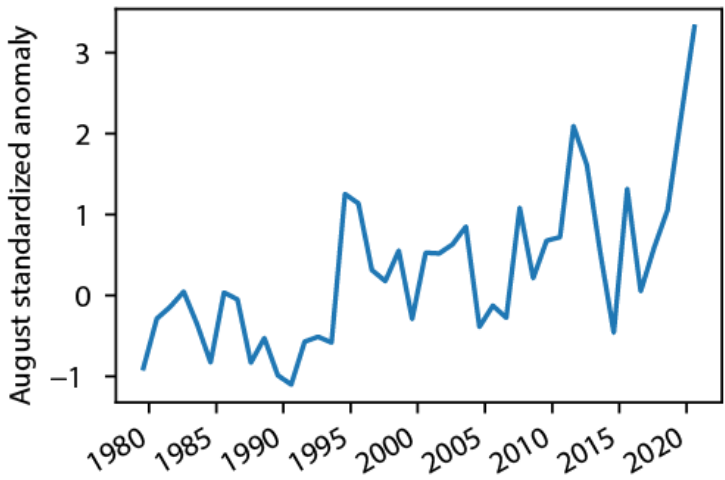

Figure 2: The domains and temperature anomalies for extreme heat over Siberia (a,c) and California-Mexico (b,d). a) March-May 2020 temperature rank within the 1979-2020 ERA5 record. Rank 1 means that temperature records were broken in 2020 . b) August 2020 standardized temperature anomaly with respect to ERA5 1979-2010 climatology. Standardized anomalies are calculated by subtracting the mean and diving by the standard deviation. Thick black lines indicate the selected domains, which for (a) is the region where March-May 2020 temperature records were broken over Siberia, and for (b) is where August temperature anomalies exceeded twice the climatological standard deviation. c,d) The standardized temperature anomalies averaged over the domains indicated in (a,b).

\section{Step 2: Select an appropriate prediction system}

Increasing computational resources and improved physical understanding of the Earth System have led to advances in seamless prediction systems over recent decades (Alley et al., 2019; Bauer et al., 2015; Hoskins, 2013; Palmer, 2019). Yet, different forecast timescales have varying benefits and drawbacks with respect to the UNSEEN approach. Hence, the type of weather event that is being studied should inform the choice of prediction system (Figure 3). Predictions ranging from weeks to years provide high-resolution but independent events well suited for regional-scale multi-day to monthly events, such as heatwaves (Cowan et al., 2020; Kay et al., 2020; Thompson et al., 2019), cold spells, wind storms (Walz and Leckebusch, 2019) and extreme precipitation (Jain et al., 2020; Kelder et al., 2020; Thompson et al., 2017) (Figure 3). For sub-daily extremes - such as ocean wind and wave 
extremes, convective storms, or wind gusts - high-resolution simulations are required to resolve sub-grid processes (Sillmann et al., 2017). In general, global medium-range simulations (10-15 days) are likely to be most appropriate for studying local, short-duration events (e.g. Breivik et al., 2014, 2013; Meucci et al., 2018; Osinski et al., 2016), or additional downscaling might be needed (e.g. Guillod et al., 2018). For events with long persistence such as droughts, the ensemble members from medium-range predictions are unlikely to be unique (low independence, BOX B). Hence, decadal predictions (1-10 years) are recommended for events with long memory (e.g. Hall et al., 2020, 2019; Kay et al., 2018).

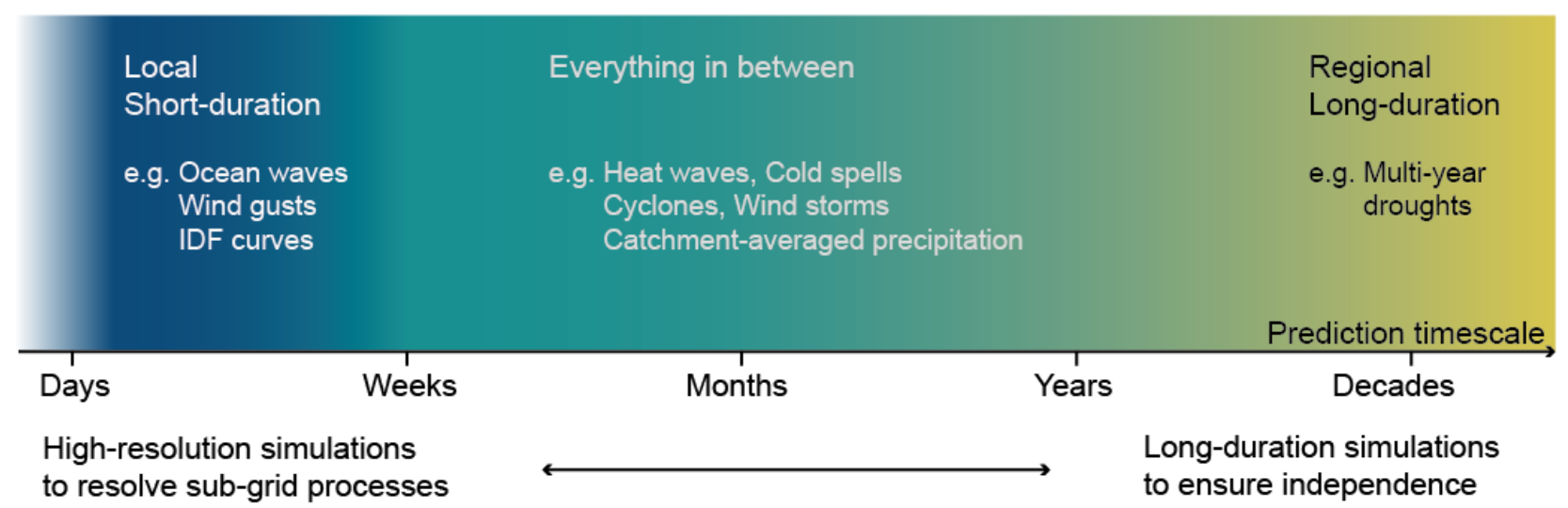

Figure 3: The appropriateness of hindcast ensembles for different types of events. This schematic shows which prediction systems are most likely to be appropriate for different types of extreme events. The horizontal axis represents seamless prediction timescales, where the arrows beneath indicate the different weather prediction systems covering the respective prediction timescales. The corresponding types of extreme event range from local, short-duration events requiring high-resolution simulations, to regional, persistent events involving longduration simulations. The gradual shading indicates that multiple prediction systems might be equally appropriate for some type of events. Fading on the left-hand side is a reminder that the first few days of forecasts cannot be used because of low independence between ensemble members due to similar initial conditions. The schematic is based on Table 1.

Table 1: Hydro-meteorological extremes (variable) with spatial resolution and timescale that have been studied by pooling ensembles from medium-range, seasonal, and decadal prediction systems. Note that we present the spatial resolution of the most recent prediction systems for consistency, but some of the cited studies may have used earlier systems with lower resolutions (for the data sources see Table 3).

\begin{tabular}{|l|l|l|l|l|}
\hline $\begin{array}{l}\text { Prediction } \\
\text { timescale }\end{array}$ & Variable & Spatial resolution & Timescale & References \\
\hline $\begin{array}{l}\text { Medium- } \\
\text { range }(10-15 \\
\text { days) }\end{array}$ & $\begin{array}{l}\text { Ocean wind speed and } \\
\text { wave height; } \\
\text { windstorms }\end{array}$ & $0.1^{\circ} \mathrm{x} 0.1^{\circ} ; 0.25^{\circ} \mathrm{x} 0.25^{\circ}$ & $6 \mathrm{~h}$ & $\begin{array}{l}\text { Breivik et al., 2014, 2013; Osinski et al., } \\
2016 ; \text { Meucci et al., 2018 }\end{array}$ \\
\hline $\begin{array}{l}\text { Extended- } \\
\text { range (22-46 } \\
\text { days) }\end{array}$ & Floods & $5 \mathrm{~km} \times 5 \mathrm{~km}$ & day & Brunner and Slater, 2021 \\
\hline $\begin{array}{l}\text { Seasonal (6 } \\
\text { months) }\end{array}$ & $\begin{array}{l}\text { Rainfall; } \\
\text { wind losses; } \\
\text { river discharge }\end{array}$ & $0.4^{\circ} \mathrm{x} 0.4^{\circ} ; 1^{\circ} \mathrm{x} 1^{\circ}$ & $\begin{array}{l}6 \mathrm{~h} ; 3 \text { days; } \\
\text { season }\end{array}$ & $\begin{array}{l}\text { van den Brink et al., 2005, 2004; Walz and } \\
\text { Jain et al., 2020; Kelder et al., 2020 }\end{array}$ \\
\hline
\end{tabular}




\begin{tabular}{|l|l|l|l|l|}
\hline $\begin{array}{l}\text { Decadal (1- } \\
10 \text { years) }\end{array}$ & $\begin{array}{l}\text { Rainfall; temperature; } \\
\text { water shortage; } \\
\text { drought }\end{array}$ & $\begin{array}{l}0.5^{\circ} \mathrm{x} 0.5^{\circ} ; \\
1.875^{\circ} \mathrm{x} 1.25^{\circ} \mathrm{GCM}, \\
0.22^{\circ} \mathrm{x} 0.22^{\circ} \mathrm{RCM}\end{array}$ & $\begin{array}{l}\text { day; month; } \\
\text { season }\end{array}$ & $\begin{array}{l}\text { Thompson et al., 2019, 2017; Kent et al., } \\
2019,2017 ; \text { Kay et al., 2020. Kay et al., } \\
2018 ; \text { Hall et al., 2020,2019 }\end{array}$ \\
\hline
\end{tabular}

\section{Step 3: Retrieve the ensemble hindcast and reference dataset}

The UNSEEN-open technical workflow was developed for steps 3-5 of the protocol with a focus on the SEAS5 prediction system, but with other systems from Copernicus Climate Change Services (C3S) also in mind (see Figure 1 and supporting technical documentation: https://unseen-open.readthedocs.io). The protocol is applicable to any prediction system, whilst the code and guidance for UNSEEN-open is developed to work with the Copernicus Data Store (CDS, https://cds.climate.copernicus.eu/). For the case studies presented here, we retrieve all relevant SEAS5 forecasts, ERA5 reanalysis, and EOBS observational data from CDS via a Python API (https://pypi.org/project/cdsapi/). Jupyter notebooks showing how the data are retrieved are available at https://unseen-open.readthedocs.io/en/latest/Notebooks/1.Download/1.Retrieve.html. SEAS5 data dimensions and retrieval time are optimized by (1) retrieving pre-computed monthly statistics (minimum, maximum or average) instead of retrieving all forecasts in full; (2) selecting only the target domain and months, then converting those into the relevant initialization months and lead times required for the request and; (3) optimizing retrieval functions to the structure of the ECMWF MARS archive (see the ECMWF documentation).

SEAS5 ensemble members and lead times are pooled to create the UNSEEN ensemble (e.g. Kelder et al., 2020). For example, UK February precipitation is forecasted from 6 initialization months (i.e., the preceding September to February, Figure 4a). For longer duration 'target events', such as March-April-May average temperature over Siberia, there are fewer forecasts that can be pooled together (from 4 initialization months, i.e., the preceding December to March, Figure 4b). We discard the first month of the forecast because ensemble members are still likely to be overly constrained to initial conditions (Kelder et al., 2020). In the end, we are left with 5 initialization months for monthly blocks (such as the UK and California examples) and 3 initialization months for seasonal blocks (such as for the Siberia example). Pooling across the 25 ensemble members yields a potential increase to 125 (monthly blocks) and 75 (seasonal blocks) compared with a single observed period.

SEAS5 is, at present, the latest seasonal prediction system of ECMWF, launched in November 2017. SEAS5 hindcasts are run on a $36 \mathrm{~km}$ horizontal resolution and are upscaled to a $1^{\circ}$ grid to create a homogenous dataset with the same resolution for all Copernicus Climate Change Services (C3S) seasonal prediction systems. The historical seasonal predictions consist of two datasets: hindcasts (years 1982-2016) and archived forecasts (years 
2017-2020). These datasets are slightly different: the hindcasts contain 25 members whereas the operational forecasts have 51 members; and the dataset from which the forecasts are initialized are different. The hindcast dataset was originally created to evaluate and calibrate the seasonal forecasts and is publicly available. Hence, inhomogeneity between the hindcasts and forecasts is not expected, but can occur because of the slight differences in resolution and initialization. For further details on SEAS5, see the ECMWF page (https://confluence.ecmwf.int/display/CKB/C3S+Seasonal+Forecasts) and Johnson et al. (2019).

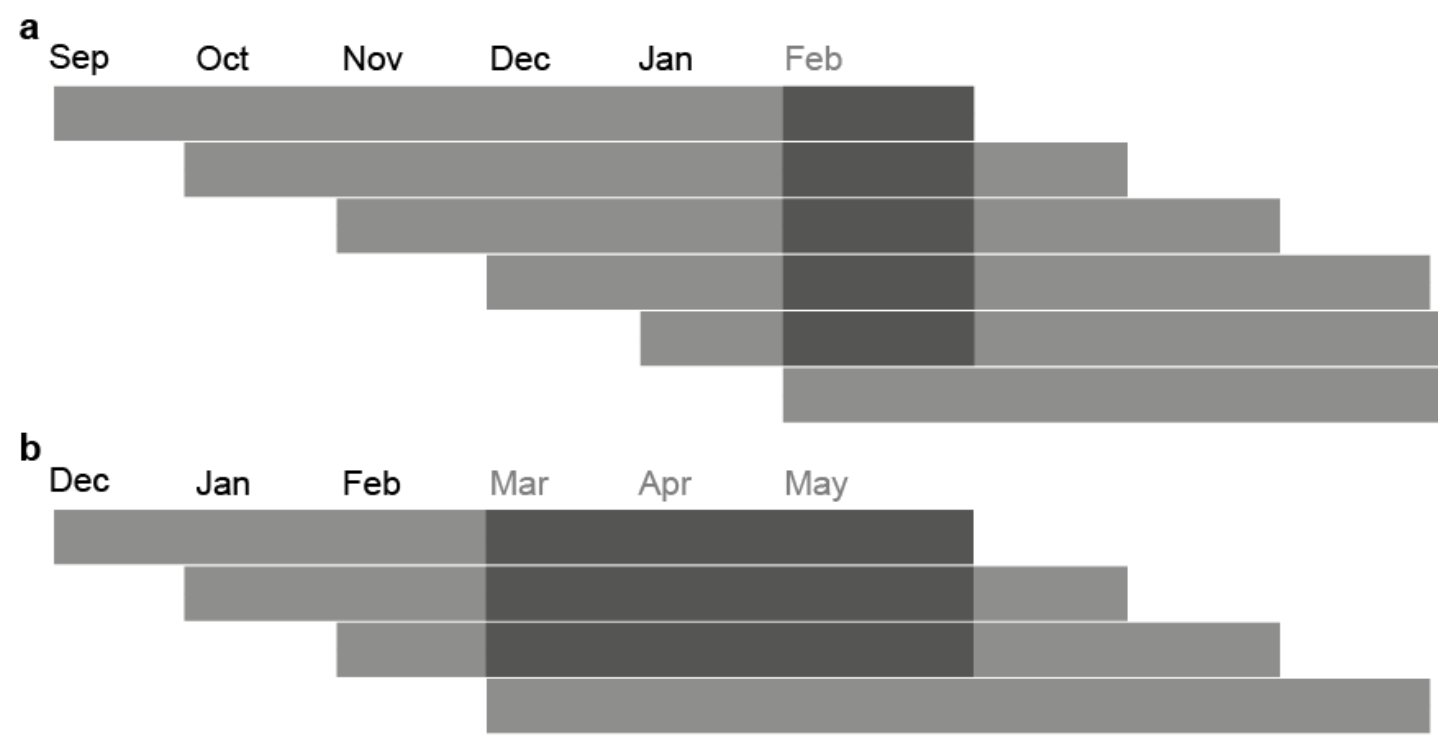

Figure 4: Schematic showing how forecasts initialized in different months can be pooled to extend the sample size for the same target event. The grey horizontal bars represent the seasonal forecasts, which are initialized every (leftmost) month and run for 6 months after their initialization. Dark shading indicates the relevant section of the target period (lead times greater than 1 month) used for the February UK precipitation (a) and March-May Siberian heat (b) case studies.

\section{Step 4: Pre-process the data}

In the pre-processing step, the retrieved files are merged into one multi-dimensional dataset (xarray, Hoyer and Hamman, 2017). This dataset can be stored as a NetCDF file containing the dimensions latitude, longitude, ensemble members, time (years) and lead time (initialization months). Then, a domain and timescale representative of the event being studied is selected. In the workflow, the resulting data array (with dimensions ensemble members, time, and lead time) is converted to a data frame (with variables ensemble members, time and lead time) and stored as a csv file to match ggplot functionalities in R. This step is provided in python and is run on a local machine. 


\section{Step 5: Evaluate the independence, stability and fidelity}

In the evaluation step, ensemble member independence, model stability, and model fidelity are tested (BOX B). Thompson et al. (2017) developed the model fidelity test and Thompson et al. (2019) discussed the general applicability also in terms of the ensemble member independence and model stability. Kelder et al. (2020) then developed methods for the evaluation of the independence and stability for a case study of extreme precipitation events over Norway and Svalbard. Here, we build upon and extend these evaluation tests so they can be tailored to the selected event definition. We provide functions for testing the three criteria in the 'UNSEEN' R-package (https://github.com/timokelder/UNSEEN). We switch from python to $\mathrm{R}$ since we believe $\mathrm{R}$ has a better functionality in extreme value statistics. This section describes the evaluation tests.

Ensemble member independence is tested by assessing the forecast predictability. If there is no predictability, the ensemble members can be assumed independent. The independence test used in this workflow is a modification of the 'potential predictability' test - the ability of the forecast to predict itself (Kelder et al., 2020; Lavers et al., 2014; Wilks, 2011). The correlation between each ensemble member is calculated, resulting in 300 distinct pairs per lead time (Kelder et al., 2020). The independence test includes detrending of values by first-differencing, whereby a new series is created from the differences between each successive value in a time series. Then, the non-parametric Spearman Rank correlation between ensemble members is compared with the correlation arising by chance from uncorrelated members. This may be represented as a boxplot of the correlations between all pairs of ensemble members, with background values for each of the boxplot statistics given by those expected between all pairs of uncorrelated members.

For example, for the Siberian heat case study, the independence test shows that there is stronger correlation between ensemble members than would be expected by chance (Figure 5). The dependence between ensemble members is most pronounced for the shortest lead time used (recalling from section 2.3 that the first month of the forecasts are removed to avoid dependence). The correlation is not caused by a trend because the time series have been detrended. 


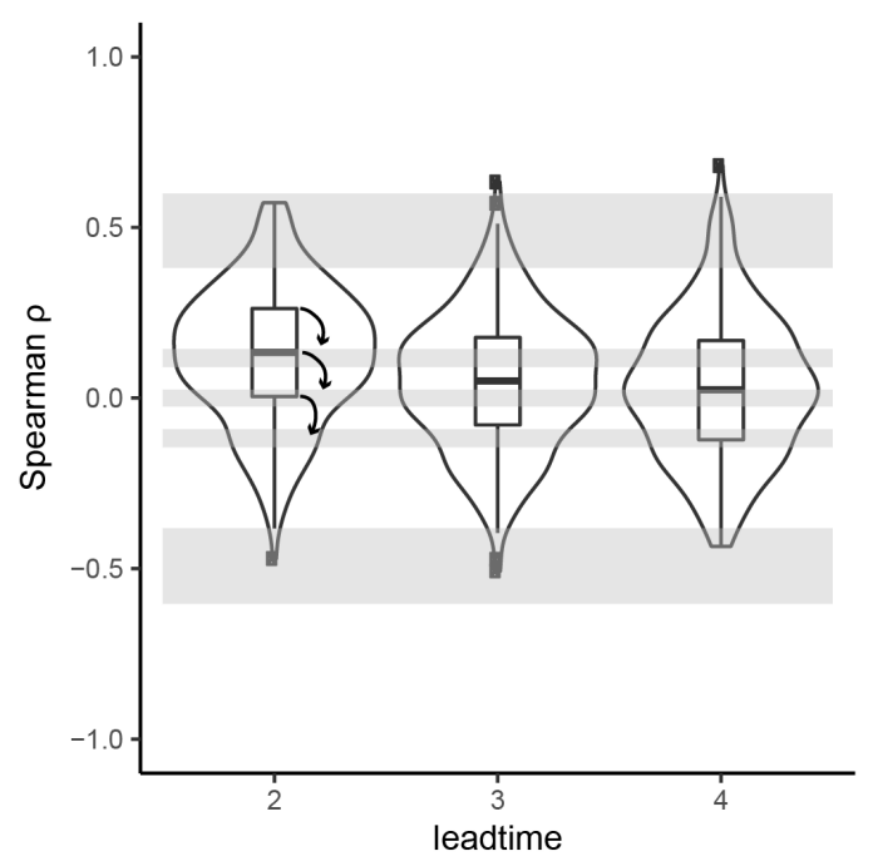

Figure 5: Example of an ensemble with inter-member dependence. Boxplots and violin plots show the correlation between all pairs of ensemble members for each lead time within the hindcast ensemble of March-May Siberian temperatures. Boxplots show the median, interquartile range, $1.5 x$ interquartile range and outliers of correlation values (small squares). Grey horizontal shading denotes the correlation (median, interquartile range and $1.5 x$ interquartile range) that is expected by chance. Arrows indicate for lead time 2 , where the median and inter-quartile range are higher than would be expected by chance, revealing that the ensemble members are not fully independent.

Model stability is tested by comparing distributions between the different lead times (Kelder et al., 2020), which is performed on the original, raw data. For example, for the California wildfire danger case study, we find that August temperatures tend to drift over forecast lead time (Figure 6). First, the probability density function is plotted for each lead time (Figure 6a). This shows that lead time 6 seems to be colder for the tail of the distribution, which contains the extreme values of interest. Then, an empirical extreme value distribution is plotted (Figure 6b), which focusses more on the tail of the distribution. The extreme value distributions show that the drift is less pronounced for rare events. For more details about the model stability test refer to Kelder et al. (2020). 

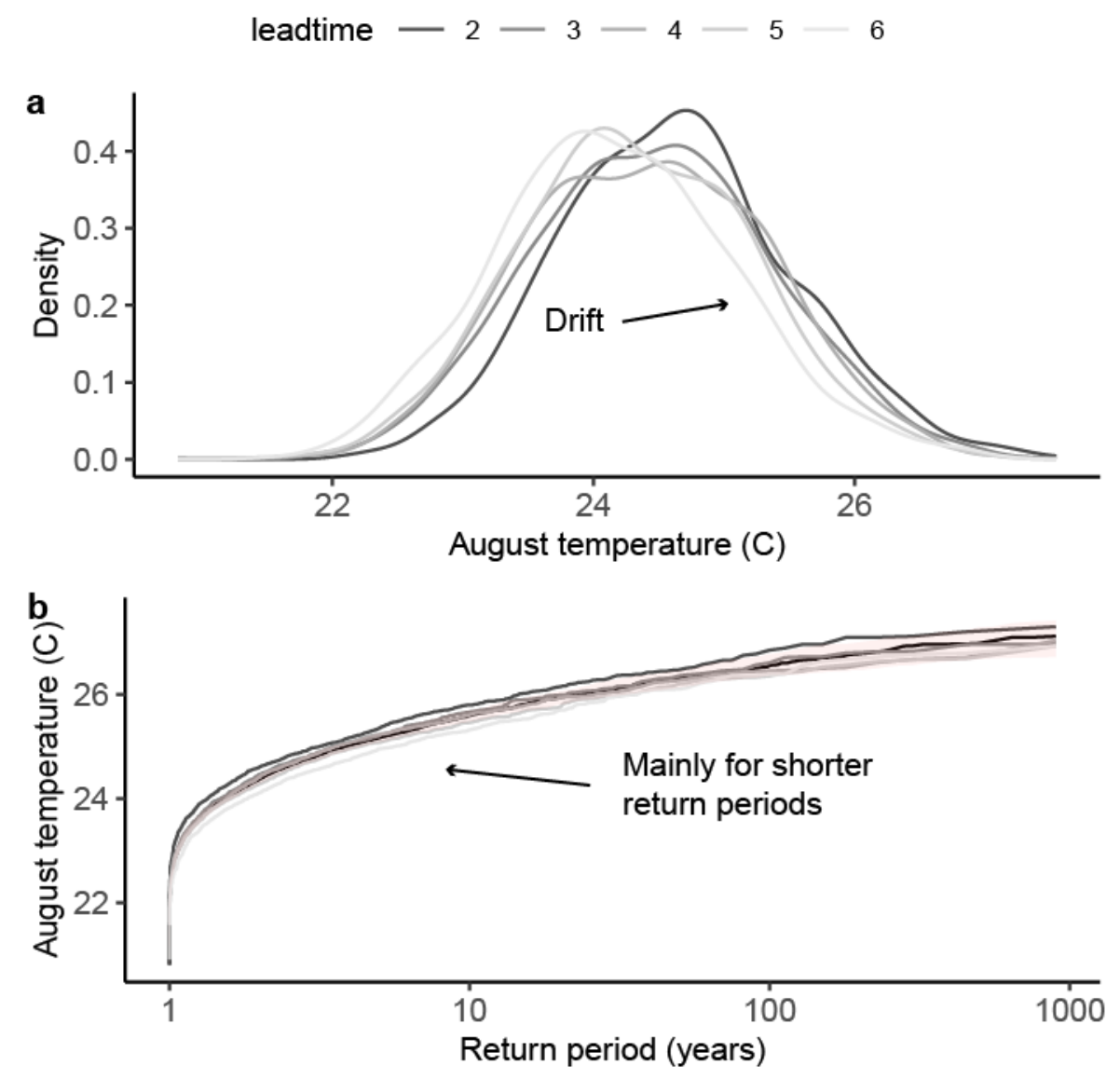

Figure 6: Testing the model stability for August California temperatures within the SEAS5 hindcast ensemble. The (a) probability density and (b) extreme value distributions are plotted for each lead time. Grey shading in (b) illustrates $95 \%$ confidence bounds. Arrows highlight the presence of model drift, most pronounced in lead time 6 for shorter return periods.

Model fidelity is tested by evaluating the consistency between the hindcast ensemble and a reference dataset. For illustrative purposes, the hindcast ensemble for February rainfall is bootstrapped into 10,000 series of equal length to the reference dataset, with all lead times pooled together (Kelder et al., 2020; Thompson et al., 2017). The mean, standard deviation, skewness, and kurtosis are calculated for each of the series. Histograms of these distribution characteristics are plotted, including their $95 \%$ confidence interval. The range of the distribution characteristics within the hindcast ensemble can then be compared with the reference dataset (Figure 7). 

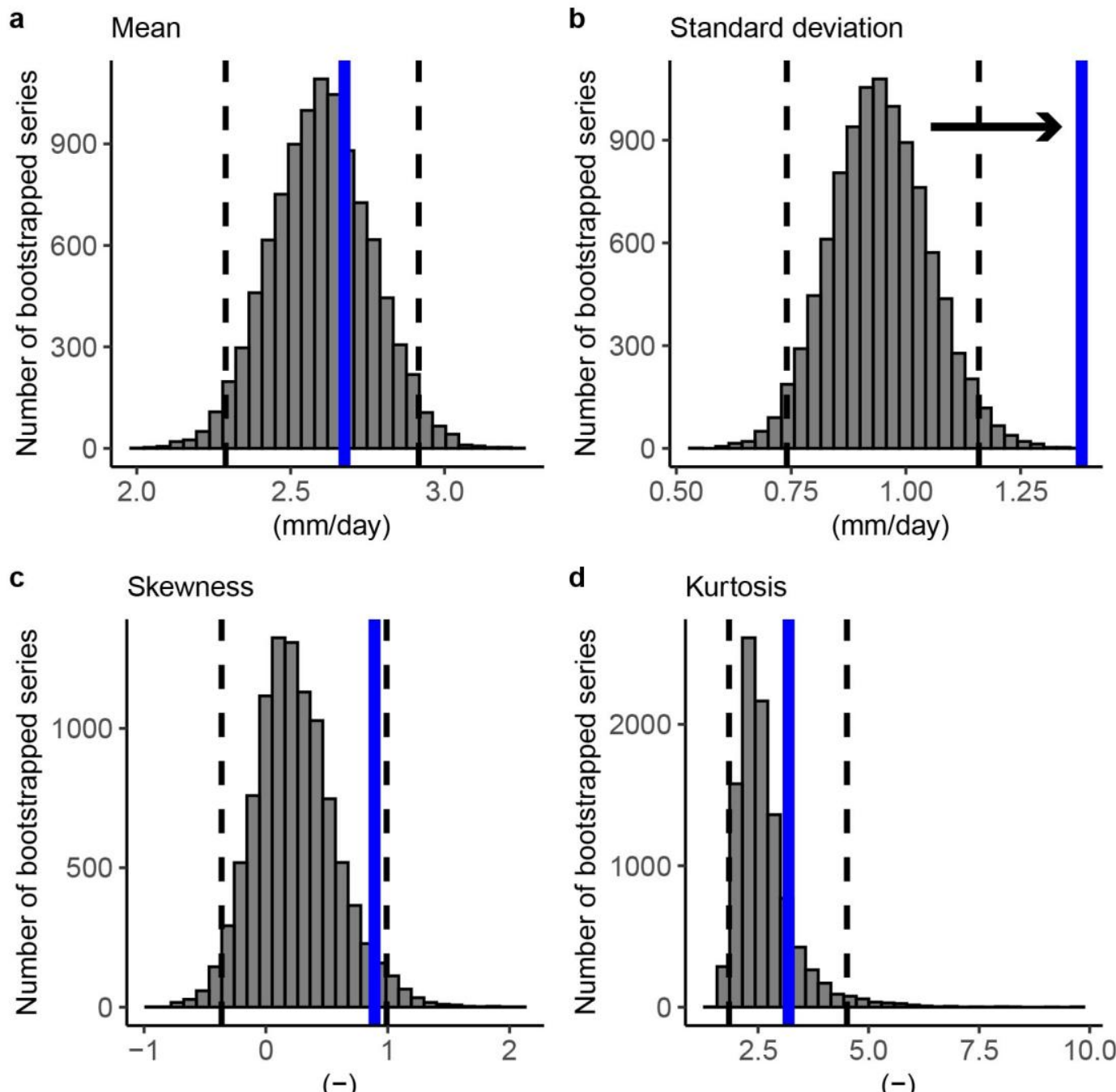

Figure 7: Testing the fidelity of UK February precipitation simulations within the SEAS5 hindcast. Distribution characteristics of SEAS5 are compared with EOBS. Histograms show the distribution of the (a) mean (b) standard deviation (c) skewness and (d) kurtosis for SEAS5, including 95\% confidence intervals (dashed lines). EOBS statistics are derived for the period 1981-2016 (blue lines). The arrow denotes where the moment from EOBS lies outside the confidence interval of the SEAS5 ensemble - in this case for the standard deviation.

\section{Step 6: Resolve detected issues}

If the above three tests are passed, the ensemble is considered credible for applications (Figure 1). However, if one or more tests fail, identified issues need to be resolved prior to further use. This section discusses potential solutions to resolve the issues, which are summarized in Table 2 . 
Table 2: Potential solutions when issues with ensemble member independence, stability, or fidelity are detected.

\begin{tabular}{|l|l|l|}
\hline Independence & Stability & Fidelity \\
\hline $\begin{array}{l}\text { Solution I1: Remove problematic lead } \\
\text { times }\end{array}$ & $\begin{array}{l}\text { Solution S1: Remove problematic lead } \\
\text { times }\end{array}$ & $\begin{array}{l}\text { Solution F1: Additive / multiplicative } \\
\text { adjustment }\end{array}$ \\
\hline $\begin{array}{l}\text { Solution I2: Assess whether forecasts are } \\
\text { over-dispersed or under-dispersed }\end{array}$ & $\begin{array}{l}\text { Solution S2: Bias adjust individual lead } \\
\text { times }\end{array}$ & Solution F2: Apply other evaluation tests \\
\hline $\begin{array}{l}\text { Solution I3: Assess the spread in large- } \\
\text { scale physical drivers }\end{array}$ & & $\begin{array}{l}\text { Solution F3: Evaluate drivers and feedback } \\
\text { processes }\end{array}$ \\
\hline $\begin{array}{l}\text { Solution I4: Calculate the effective sample } \\
\text { size }\end{array}$ & & \\
\hline
\end{tabular}

When the independence test or stability tests are failed, the simplest solution is to remove the problematic lead times (Solution I1 in Table 2). If ensemble member dependence cannot be corrected by removing problematic lead times - for example when dependence persists across all lead times - it is possible to assess whether forecasts are over-dispersive or under-dispersive (Solution I2 in Table 2) by calculating the signal-to-noise ratio and/or the relationship between ensemble mean root-mean-square error (RMSE) and ensemble spread (e.g. Weisheimer et al., 2019). Another desirable (but not always practical) approach is to assess the spread in large-scale physical drivers and surface states relevant to the hydro-climatic extreme being studied (Solution I3), such as sea-surface temperatures, sea-ice conditions, soil moisture, or atmospheric patterns. The spread shows the extent to which the ensemble is tied to slowly varying properties within the prediction systems. A bounded ensemble can still provide valuable information. In fact, many weather generators are constructed to be constrained and bounded to typical weather types. Therefore, predictability is only an issue when it originates from the initial conditions. Initialcondition predictability implies that the ensemble members are not unique, whereas predictability from boundary conditions means that the ensemble members are unique but conditioned. Note that for events with short memory and low persistence, no initial-condition predictability is expected beyond two weeks (Lorenz, 1963). Finally, the option to calculate the effective sample size (Solution I4) is recommended when dependence remains an issue (Breivik et al., 2013). The effective sample size represents the size of the dependent sample that an independent sample would have. For example, an ensemble consisting of 1000 years of weather events containing some dependence may effectively represent only 500 unique, independent years. For an ensemble with sample size $(N)$ 
that expresses dependence (correlation between ensemble members, $r$ ), the effective sample size $\left(N^{*}\right)$ can be calculated following Breivik et al. (2013):

$$
N^{*}=\frac{N}{1+(N-1) * r}
$$

If model stability is an issue and cannot be corrected by removing problematic lead times (Solution S1 in Table 2), each lead time can be bias adjusted separately (Solution S2). However, the type of bias adjustment should be carefully considered. The UNSEEN ensemble may sample plausible extreme events that never occurred, and bias adjustment techniques may constrain the ensemble to observed extremes - thereby removing information about unseen events. Furthermore, observations are not the 'truth' under internal variability, resolution mismatch and other sources of error (Casanueva et al., 2020; Wilby et al., 2017). Attention is needed to evaluate which statistical properties of the extremes are being constrained to observations. For systematic biases, additive (for temperature) or multiplicative (for precipitation) adjustment may be applied (Jain et al., 2020; Kelder et al., 2020; Thompson et al., 2019). When inconsistencies in the variability (standard deviation) or shape (skewness and kurtosis) remain, the Inter-Sectoral Impact Model Intercomparison Project (ISI-MIP, Warszawski et al., 2014) bias adjustment approach (Hempel et al., 2013; Lange, 2019), which is commonly used to study climate impacts (e.g. Mitchell et al., 2017), may be applied with caution. For more guidance on bias adjustment methods see for example Cannon et al. (2020) and Maraun and Widmann (2018).

When model fidelity is an issue, an additive or multiplicative adjustment can be applied (Solution F1). If issues with model fidelity remain, it is recommended to apply other evaluation tests (Solution F2) plus assess large-scale drivers and land surface feedbacks related to the extreme event (Solution F3).

In this workflow the fidelity test was used for its focus on rare extremes. The sensitivity of the model fidelity results to the method of assessment can be tested (Solution F2). A wide range of methods and tools to identify biases in the simulation of extreme events exist (Eyring et al., 2019) that can be applied as tests for UNSEEN applications. For example, the 'ESMValTool' has been developed for climate model evaluation (Eyring et al., 2016) including extreme events (Weigel et al., 2021). Furthermore, metrics common to the evaluation of numerical weather prediction systems, such as the forecast reliability and rank histograms, can be used for prediction systems across timescales (Bellprat et al., 2019; Palmer and Weisheimer, 2018; Suarez-Gutierrez et al., 2021; Weisheimer and Palmer, 2014). In addition to the statistical evaluation methods presented so far, it may be desirable to evaluate the 
large-scale drivers and feedback processes of the extreme events (Solution F3) and how they are represented in the model (e.g. van der Wiel et al., 2017; Vautard et al., 2019). For example, Kay et al. (2020) and Thompson et al. (2019) assessed the large-scale drivers of simulated unseen temperature events.

\section{Case studies}

We now present three case studies where we apply the UNSEEN protocols to the 2020 Siberian heatwave, temperature anomalies during peak California wildfire activity, and UK extreme precipitation events. We describe the steps taken to generate and evaluate the UNSEEN ensemble for each of the case studies. When issues are identified, the options to resolve them are discussed and appropriate solutions applied. The potential of the UNSEEN method is illustrated for the cases where the ensemble is deemed credible.

\subsection{Siberian heatwave}

The detailed technical steps involved in producing this example may be followed at https://unseenopen.readthedocs.io/en/latest/Notebooks/examples/Siberian_Heatwave.html.

For the Siberian heat case study, our choice of domain and duration was informed by the location and season in which monthly temperature records were broken (section 2 and Figure 2a). We selected the area bounded by 65$120^{\circ} \mathrm{E}, 50-70^{\circ} \mathrm{N}$ for the March-May (MAM) season. Seasonal predictions (SEAS5) were selected as the hindcast ensemble and reanalysis (ERA5) was chosen for reference data. All forecasts simulating March-May monthly temperatures were retrieved and pre-processed (averaged and merged) to represent the event definition. Time series show that the 2020 event was the highest within the ERA5 record and exceeded the simulations within the UNSEEN ensemble (blue cross compared with grey boxplot in Figure 8a). One interpretation is that the 2020 event was rarer than the 75 ensemble members within UNSEEN; another is that UNSEEN does not represent the true likelihood of such an extreme event. Therefore, an evaluation of the applicability of UNSEEN for this event definition is crucial. We find some ensemble member dependence for lead time 2 (Figure 8b) but no drift over any lead times (Figure $8 \mathrm{c}-\mathrm{d})$. The fidelity test using all lead times shows that there is a cool bias in SEAS5 MAM temperatures compared with ERA5 (Figure 8e). The standard deviation, skewness and kurtosis are not significantly different (Figure 8f-h). Note that the difference between SEAS5 and ERA5 could also be due to temperature overestimation by ERA5 for this particular season and domain. However, Ciavarella et al. (2021) report little difference between ERA5 and GISTEMP 250-km anomalies (Hansen et al., 2010) for the Siberian heat event. 
Lead time 2 could be removed from the ensemble to avoid dependence (Solution I1 in Table 2). We choose to keep the ensemble members because of the low dependence for lead time 2. We apply a mean bias adjustment (Solution F1) to solve the issue with the cold bias of the UNSEEN ensemble (Supplementary Figure 1). The resulting biasadjusted UNSEEN ensemble then captures the 2020 event, along with five thawing events (MAM mean temperature $>0{ }^{\circ} \mathrm{C}$ ), with a near possibility as early as the 1990 s (Figure 9). In comparison, there had been no observed thawing events within the reanalysis prior to 2020 .

Note that the causes of the dependence and the sensitivity of the dependence result to other tests can be further assessed (Solutions I2-4 in Table 2). With a low SEAS5 standard deviation (although not statistically significant from ERA5 at the 95\% confidence level), further evaluation tests can be applied (Solution F2), and large-scale drivers and land surface feedbacks that might be unrealistic can be assessed (Solution F3). These may include feedbacks involving soil moisture or snow cover. The variability within SEAS5 could also be compared with other datasets (section 4.2). For a detailed multi-model and multi-method analysis on the change in the likelihood of occurrence of this event and the attribution to human influences, see Ciavarella et al. (2021). 
a

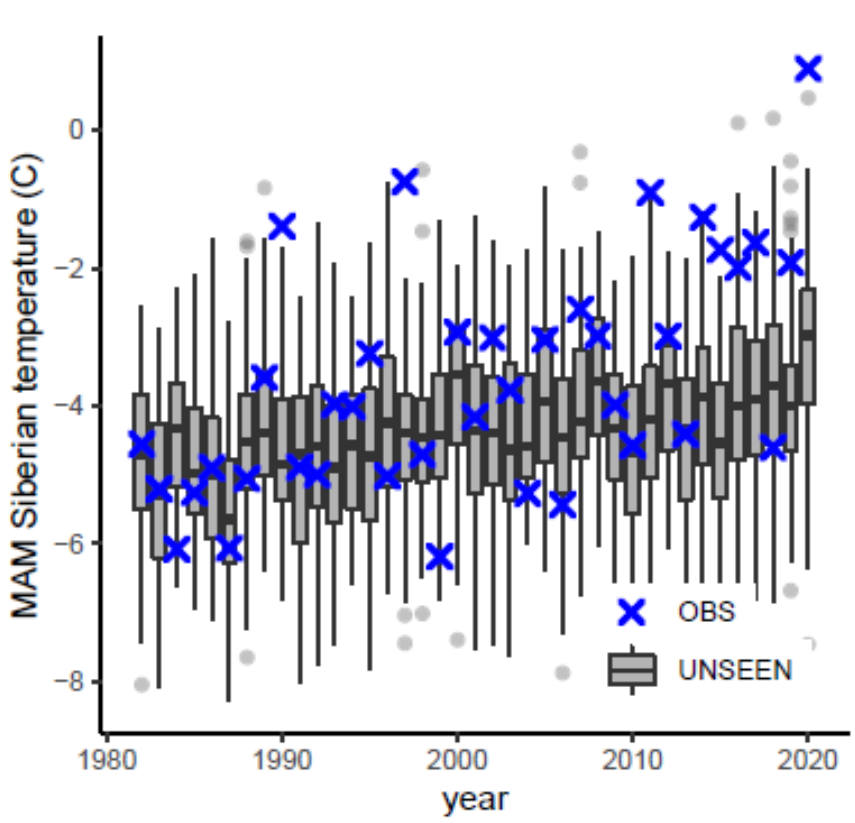

leadtime $-2-3-4$

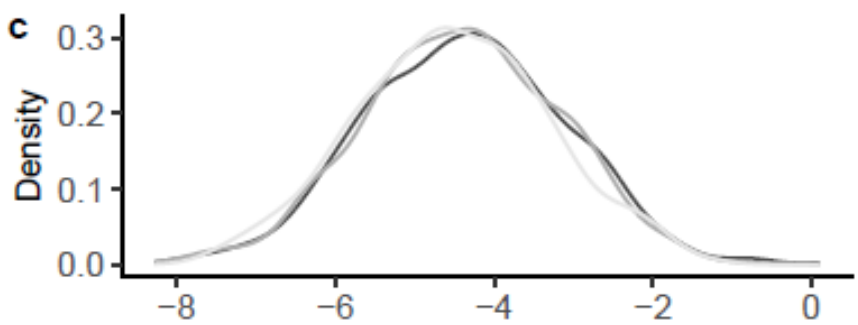

MAM temperature (C)

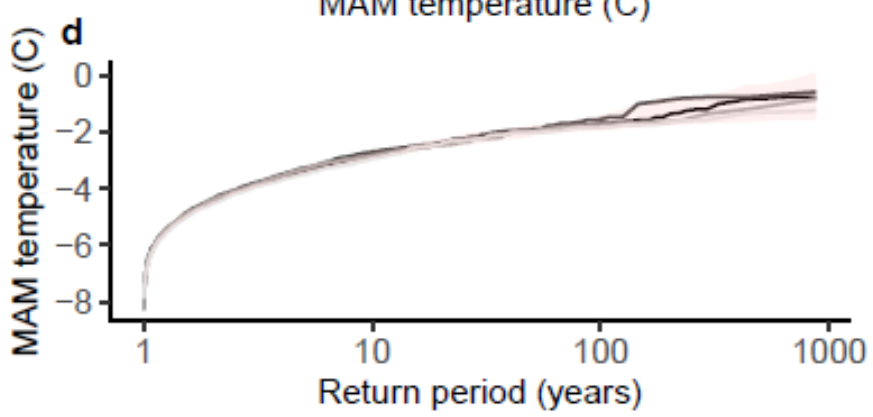

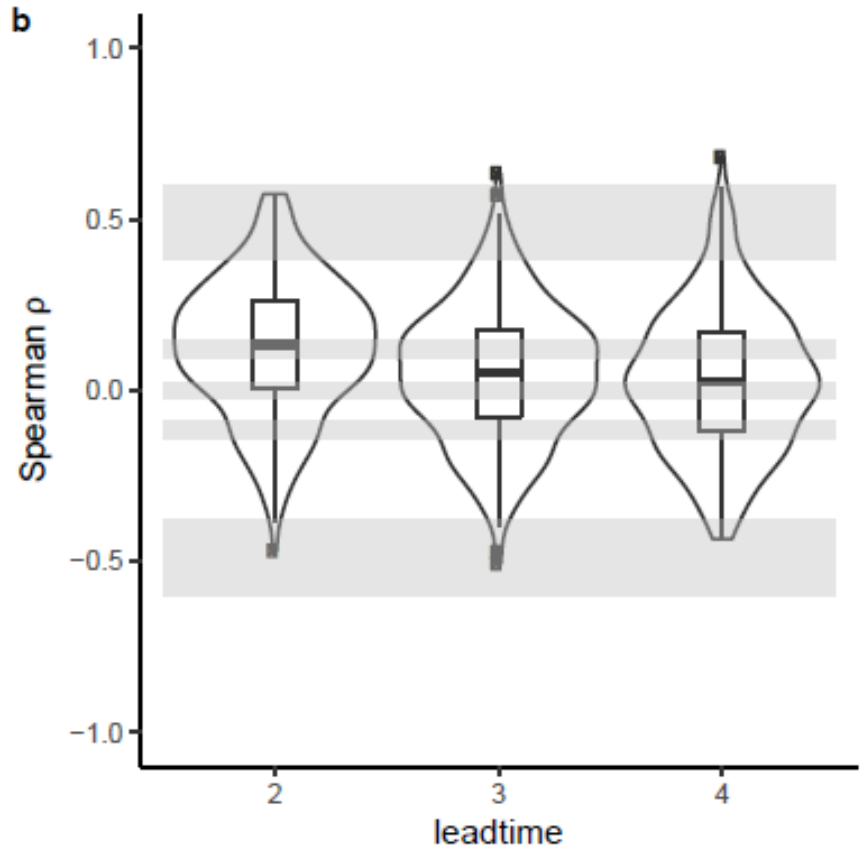

e Mean

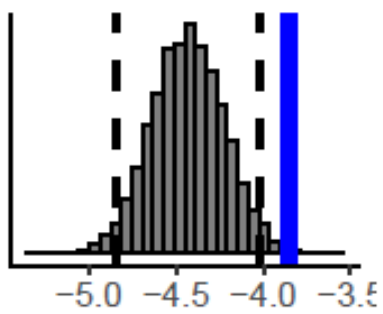

(C)

g Skewness

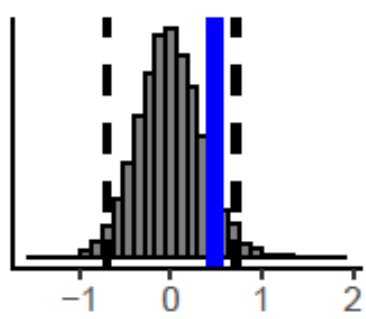

(-) f Standard deviation

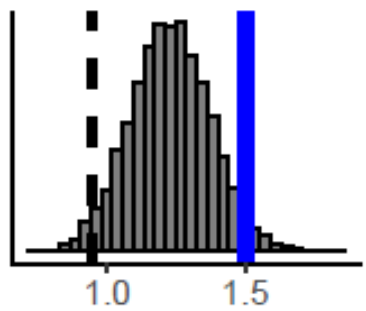

(C) h Kurtosis

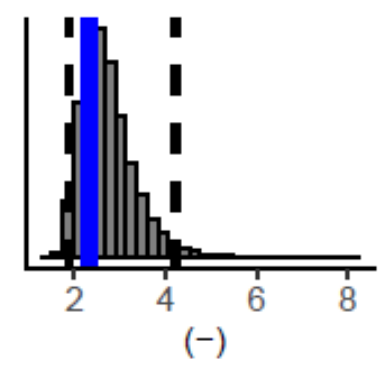

Figure 8: The (a) time series (b) independence (c-d) stability and (e-h) fidelity of the ensemble for March-May 2020 Siberian temperatures. a) Blue crosses denote events in ERA5 (OBS) and grey boxplots represent the 75 events per year in the raw unadjusted SEAS5 hindcast (UNSEEN). Boxplots show the median, inter-quartile range, $1.5 \mathrm{x}$ interquartile range and outliers (data outside the $1.5 \mathrm{x}$ interquartile range). b) As in Figure 5, box and violin plots show the correlation between ensemble members for each of the lead times within the hindcast ensemble. c,d) As in Figure 6 but for MAM Siberian temperature, showing the probability density (c) and extreme value distribution (d) for each lead time. Grey shading shows 95\% confidence bounds. e-h) As in Figure 7 but for MAM Siberian temperature and 
using ERA5 statistics derived for the period 1981-2016. Histograms show the distribution characteristics for SEAS5, dashed lines indicate $95 \%$ intervals and blue lines represent ERA5 statistics.

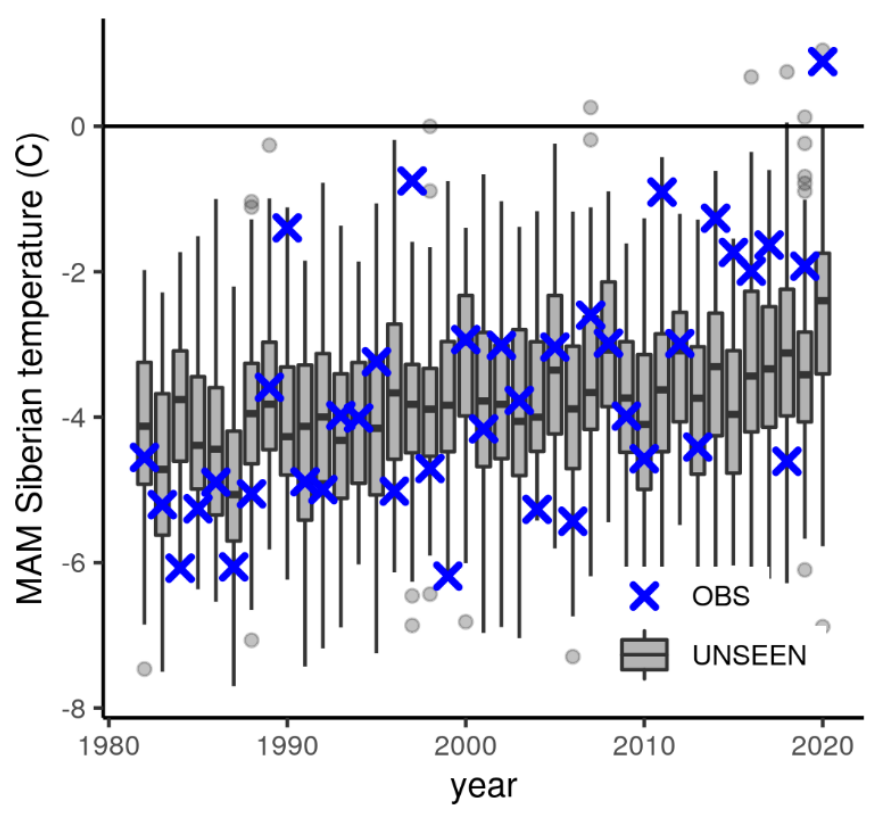

Figure 9: Thawing events over Siberia within the bias-adjusted UNSEEN ensemble compared with ERA5. As in Figure 8a, but after applying a mean bias adjustment to the UNSEEN ensemble. The horizontal line shows the threshold for thawing events (temperature $>0{ }^{\circ} \mathrm{C}$ ).

\subsection{Temperature anomalies during peak California wildfire activity}

The technical steps to reproduce this example are available at https://unseenopen.readthedocs.io/en/latest/Notebooks/examples/California Fires.html.

Selecting a meaningful metric is complicated for the California wildfire activity case study. This is because wildfire activity depends on weather conditions, as well as on fuel stock, ignition agents, and management (Flannigan et al., 2013). For example, weather conditions may be very dry, but without fuel or ignition source(s), wildfire activity is unlikely. Hence, wildfire activity cannot be studied from meteorological variables alone. However, weatherdriven fire danger conditions can be studied from such variables (e.g. Vitolo et al., 2020). For example, trends in temperature and precipitation are associated with rising likelihood of wildfire conditions across California (Goss et al., 2020). In 2020, the wildfire season peaked in August, coinciding with record high temperature anomalies (Figure 2b,d). Here, we demonstrate the applicability and potential of SEAS5 in estimating the likelihood and trend of such a temperature anomaly. We selected a contiguous, land-only region where August temperature anomalies 
were more than twice the climatological (1979-2010) standard deviation based on ERA5 over the domain 100$125^{\circ} \mathrm{W}, 20-45^{\circ} \mathrm{N}$ (Figure $2 \mathrm{~b}$ ).

a

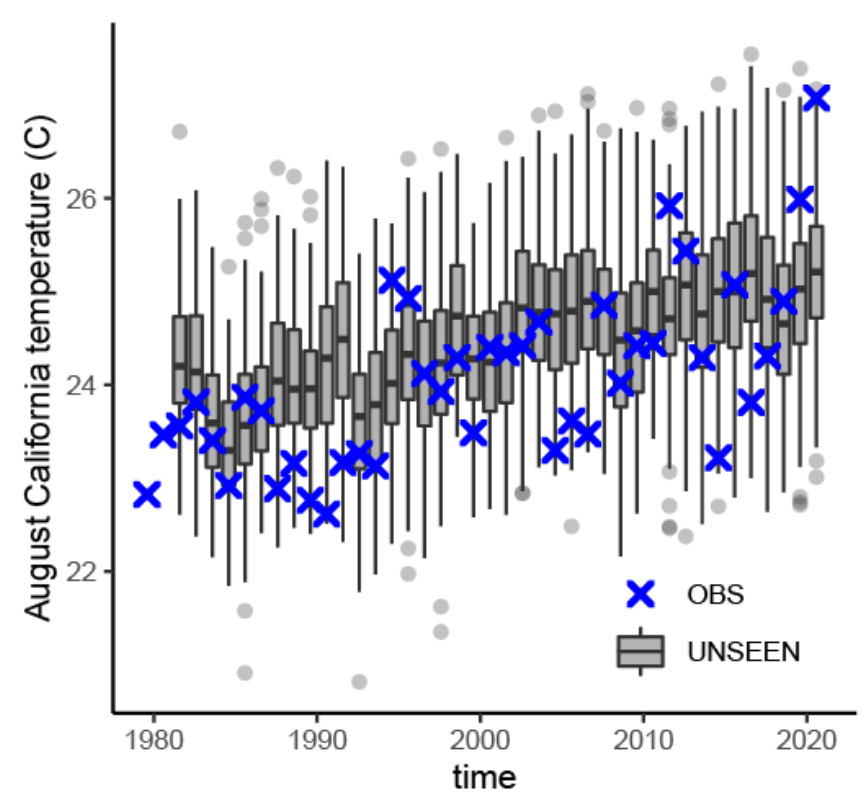

leadtime $-2-3-4-5-6$

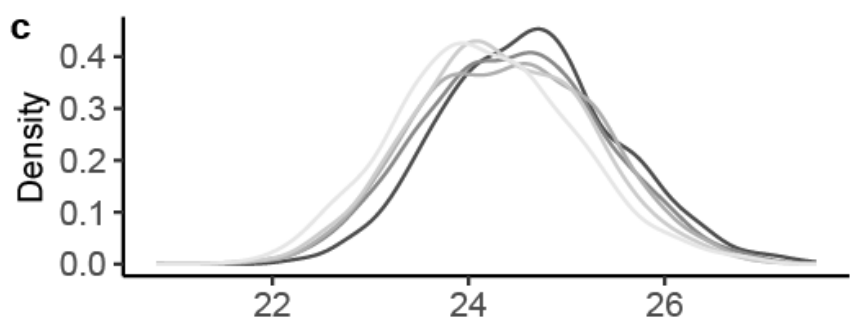

August temperature $(\mathrm{C})$

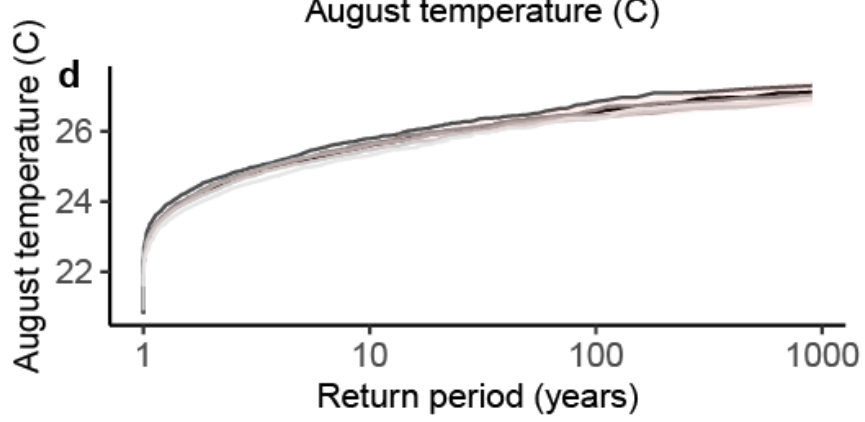

b

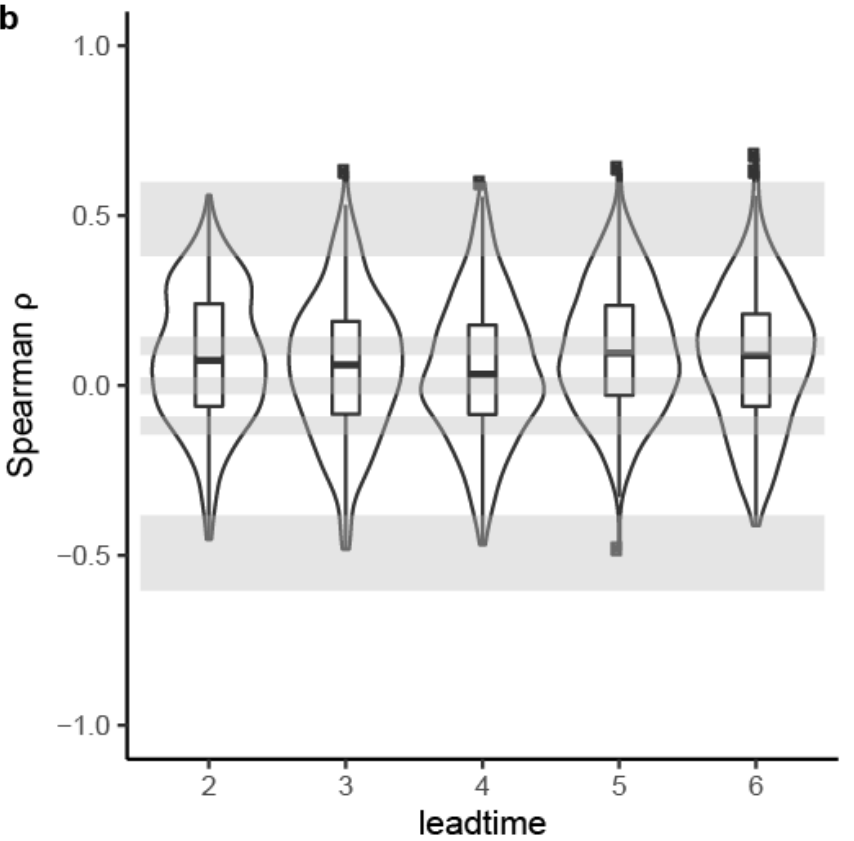

e Mean

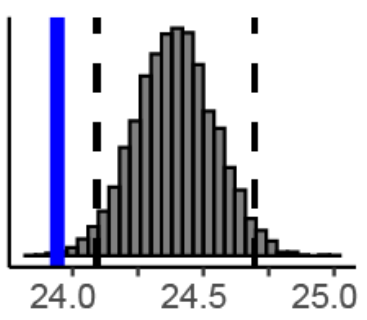

(C)

f Standard deviation

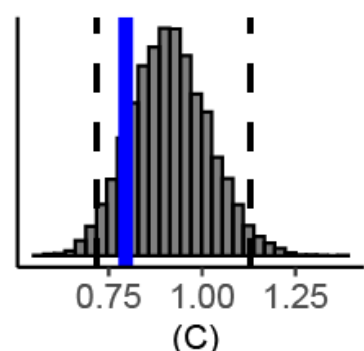

g Skewness

h Kurtosis

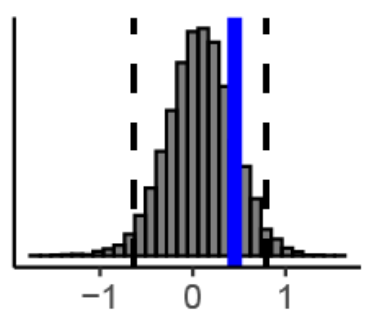

$(-)$

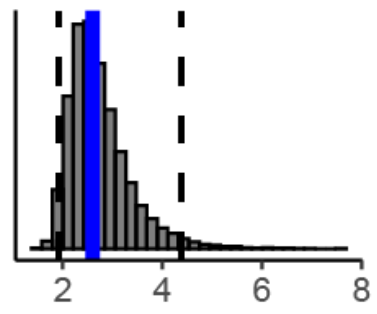

(-)

Figure 10: As in Figure 8 but for (a) time series (b) independence (c-d) stability and (e-h) fidelity of the ensemble for August temperature anomalies during peak California wildfire activity. a) Blue crosses denote events in ERA5 (OBS) and grey boxplots 
represent the 125 events per year in the raw unadjusted SEAS5 hindcast (UNSEEN). b) Box and violin plots show the correlation between ensemble members for each of the lead times for California-Mexico August temperatures within the hindcast ensemble. c,d) The probability density (c) and extreme value distribution (d) of California-Mexico August temperatures for each lead time. e-h) California-Mexico August temperature distribution characteristics for SEAS5 (histograms, including dashed lines indicating 95\% intervals) and for ERA5 derived for the period 1981-2016 (blue lines).

The ERA5 time series shows a strong increase in August temperatures over 1981-2020 for this domain, which is also present in SEAS5 (Figure 10a). We find low ensemble member dependence in the UNSEEN ensemble for all lead times (Figure 10b). We also find that the model is not stable, especially for lead time 6 the model has a cold bias (Figure 6 and Figure 10c,d). Lastly, we find that SEAS5 overestimates mean August temperatures when compared with ERA5, but that the standard deviation, skewness and kurtosis are not significantly different at a 95\% confidence level (Figure 10e-h).

Following these tests, we remove lead time 6 from the ensemble (Solution S1 in Table 2) and apply a mean bias adjustment (Solution F1), leaving 100 members in the pooled data. We use the UNSEEN-trends approach (Kelder et al., 2020) to estimate changes in extreme temperatures by fitting a nonstationary GEV distribution to the pooled UNSEEN data and to the ERA5 data, excluding the 2020 event. The trend in 2-year temperature extremes, which can be detected well within short observational records, is similar between UNSEEN and reanalysis (Figure 11a). Both reanalysis and UNSEEN suggest a strong increase in the magnitude of 100-year temperature extremes (Figure $11 \mathrm{~b}$ ), but the statistical uncertainty is much larger within the 40 -year reanalysis record (blue envelope in Figure $11 \mathrm{~b})$ than within large sample size of UNSEEN (125*40 years, orange envelope in Figure $11 \mathrm{~b})$. When we compare the GEV distributions with the 'year' covariate for 1981 as opposed to 2020, we find that the distribution of temperature for 1981 does not reach the magnitude of the 2020 event, whereas the distribution for the year 2020 does capture the event for both reanalysis and UNSEEN (Figure 11c). This result suggests that the temperature anomaly observed in 2020 could not have occurred a few decades ago and that it was still unlikely to occur in the present climate (i.e. the distribution for the year 2020), with a return period of more than 100 years, i.e., $<1 \%$ chance of occurrence.

Note that the UNSEEN-trend values shown in Figure 11 may have slightly over-confident uncertainty bounds because of the dependence between ensemble members. Removing problematic lead times is not an option (Solution I1 in Table 2) because the issue persists across all lead times. Dependence between ensemble members can be further assessed by testing whether forecasts are over-dispersive or under-dispersive (Solution I2) and by assessing the spread in relevant, slowly varying physical properties, such as sea-surface temperatures (Solution I3). Further assessment of the independence between ensemble members was not deemed necessary in this case because of the low median correlation values (Figure 10b) and because of the good match between UNSEEN and reanalysis 
(Figure 11). Furthermore, the trend may be sensitive to the estimation method and time window. As in Kelder et al. (2020), we allow the location and scale parameters to vary linearly with time. Other regression methods, other covariates than time, and other prediction systems allowing longer time periods (section 4.2) could be explored but such analyses are beyond the scope of this paper. 


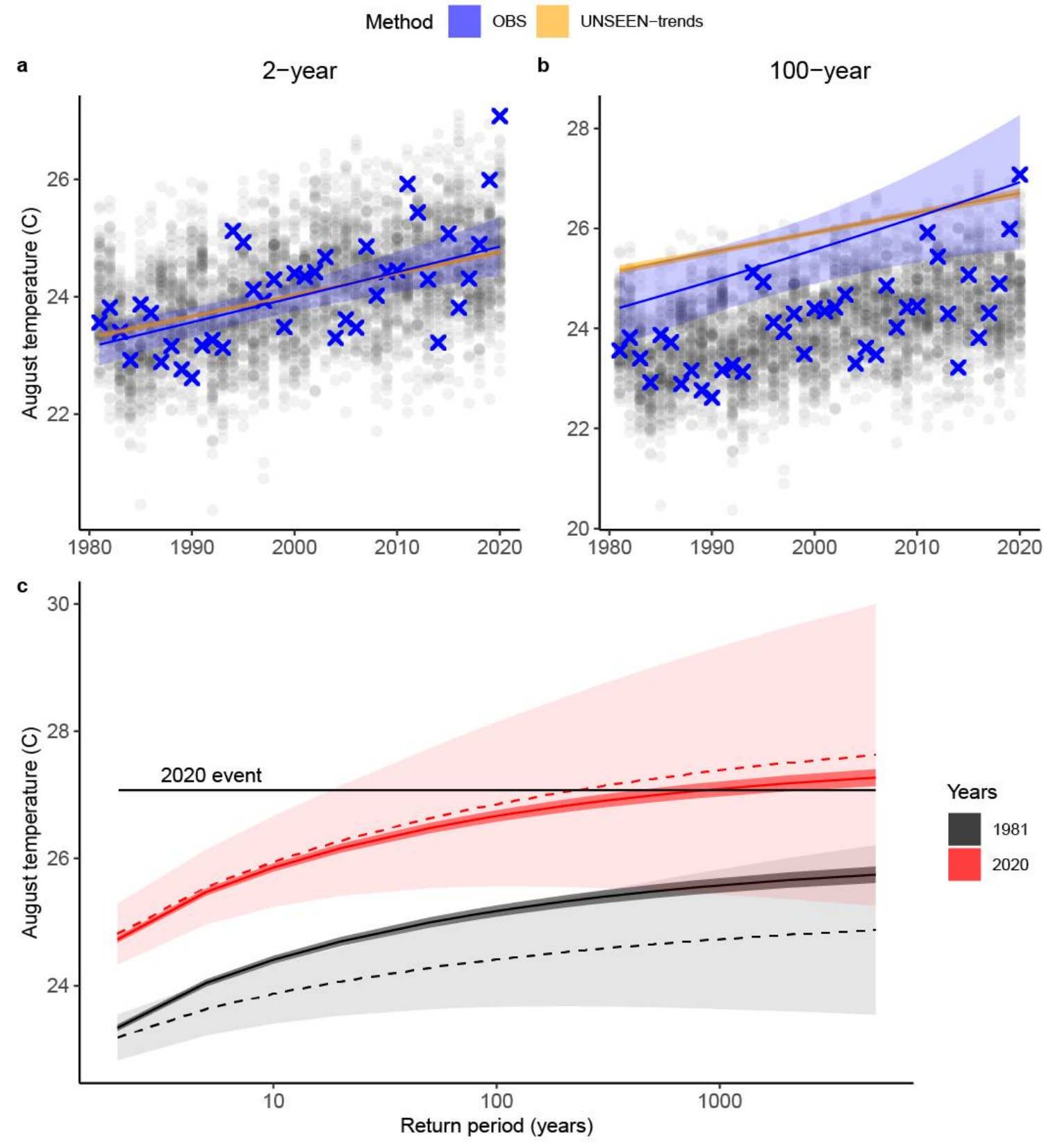

Figure 11: Trends in extreme temperatures estimated by UNSEEN and reanalysis. a,b) The temporal change in 2-year (a) and 100-year (b) August temperature extremes. Blue crosses indicate events in ERA5 (OBS). Grey circles indicate the UNSEEN ensemble. c) The GEV distribution for the covariates 1981 and 2020. Distributions based on UNSEEN are indicated by solid lines with uncertainty estimates in darker shading. The distributions based on ERA5 data are indicated by dashed lines and the uncertainty range by lighter shading ( $95 \%$ confidence intervals based on the normal approximation). The magnitude of the 2020 event is indicated with a black horizontal line. 


\subsection{UK extreme precipitation}

The technical steps to reproduce this example are available at https://unseenopen.readthedocs.io/en/latest/Notebooks/examples/UK_Precipitation.html.

Three storms hit the UK in February 2020, breaking the UK-average monthly precipitation record according to the Met Office (2020). Hence, we select country-averaged February precipitation for the UK case study. In this case, we employ the EOBS version 20.0e observational dataset as reference (Cornes et al., 2018) because precipitation observations (UK Met Office, 2020) suggest the reanalysis values may have underestimated the event. We upscale this dataset to the resolution of SEAS5 using bilinear interpolation and take the same UK spatial average as for SEAS5.

The UK February precipitation time series shows that the 2020 event was not the highest on record within the EOBS dataset (Figure 12a), while it was the highest within the HadUK-Grid dataset (Davies et al., 2021; Hollis et al., 2019). The discrepancy likely arises from the number of observation stations being incorporated, with the local HadUK-Grid dataset containing more rain gauges. Note that later versions of EOBS may have incorporated more observation stations for the year 2020 but these versions were not available at the time of analysis.

We find that SEAS5 UK February precipitation ensemble members are independent (Figure 12b) and stable (Figure 12c-d). However, there is too little variability within SEAS5 when compared to EOBS (Figure 12e-h), raising concerns about model fidelity. Independent UNSEEN analysis of February 2020 UK precipitation using the Met Office decadal prediction system and observations also found a lack of fidelity, with observed variability outside the range of that simulated (Kay 2021, personal communication). A mean bias adjustment (Solution F1 in Table 2) does not help in this case, because it will not sufficiently adjust the standard deviation. The result will likely not be sensitive to the evaluation test (Solution F2), such as a rank histogram or reliability diagram, given that the lack of variability is also evident in the time series (Figure 12a). Further evaluating the drivers (Solution F3) and comparing the results to other datasets (section 4.2) would be recommended, as the realistic simulation of large-scale winter precipitation variability over the UK may be hampered by the SEAS5's resolution. For example, Thompson et al. (2017) also found that DePreSys3 does not simulate the orographic enhancement over the Scottish highlands. Flat regions are better simulated, such as southern England.

We do not take this case study further, as the generated ensemble of UK-average February precipitation did not pass the fidelity test and could not be resolved. Note, however, that UNSEEN can successfully be applied to monthly winter precipitation over Southeast England (Thompson et al. (2017). Furthermore, for a detailed analysis 
of the dynamics of the wet Winter 2019/2020, including the attribution of the record-breaking February 2020 precipitation to climate change, see Davies et al. (2021) and Hardiman et al. (2020).
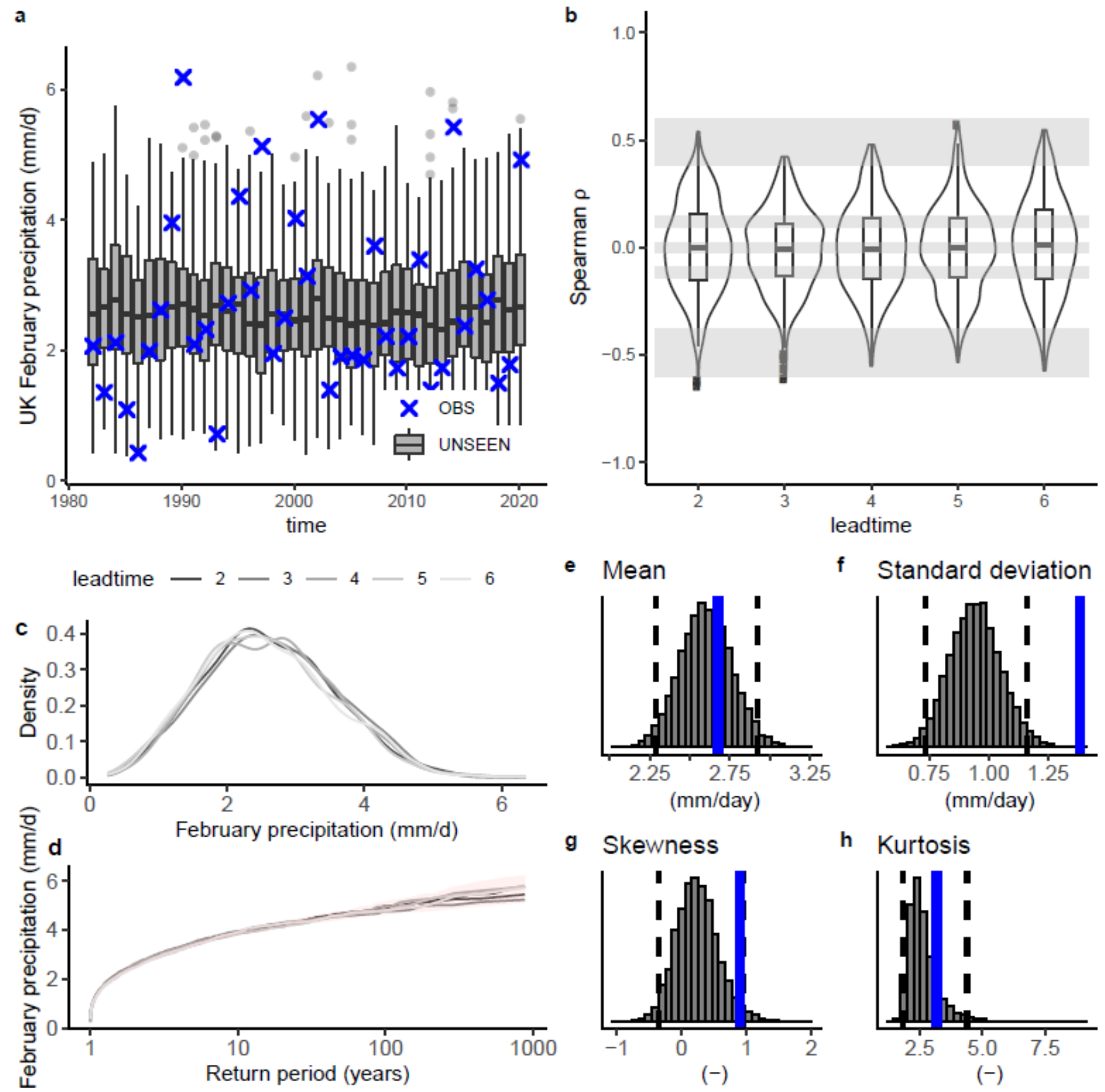

f Standard deviation
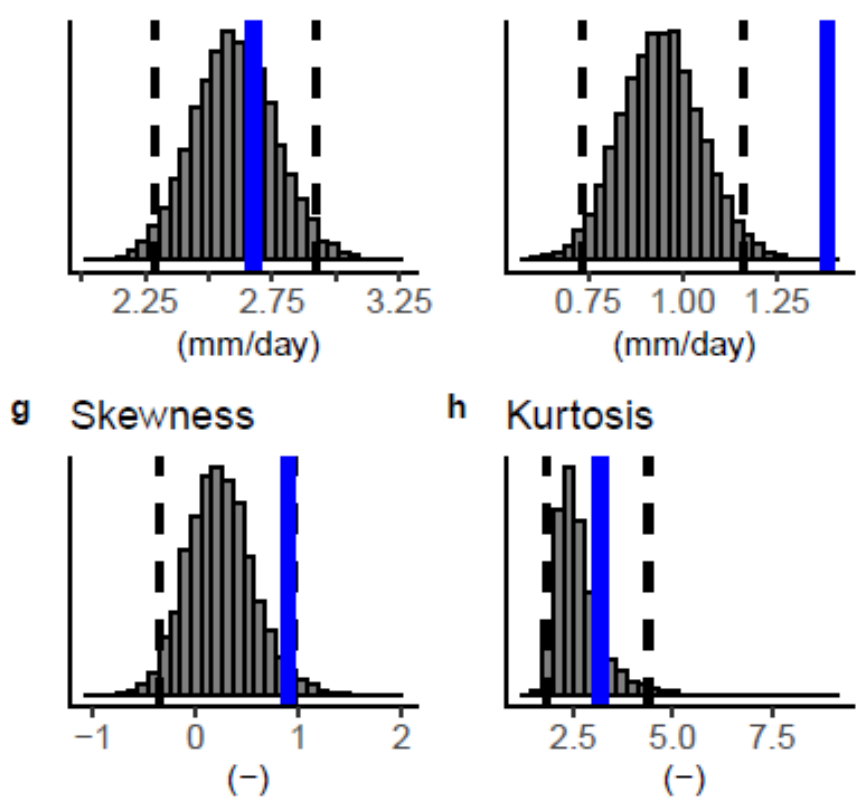

h Kurtosis

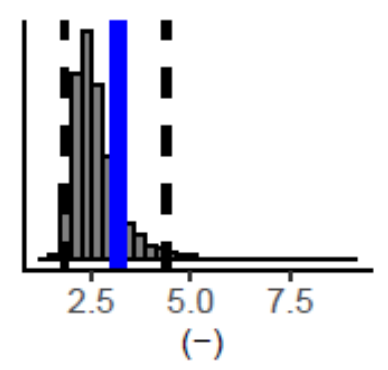

Figure 12: As in Figure 8 but for the (a) time series (b) independence (c-d) stability and (e-h) fidelity of the ensemble for February UK precipitation. a) Blue crosses denote events in EOBS (OBS) and grey boxplots represent the 125 events per year in the raw unadjusted 
SEAS5 hindcast (UNSEEN). b) Box and violin plots show the correlation between ensemble members for each of the lead times within the hindcast ensemble for UK February precipitation. c,d) The probability density (c) and extreme value distributions (d) of UK February precipitation for each lead time. e-h) The distribution characteristics of UK February precipitation for SEAS5 (histograms, including dashed lines indicating 95\% intervals) and for EOBS derived for the period 1981-2016 (blue lines).

\section{Discussion}

This paper sets out a protocol for generating a credible, large ensemble for event definitions specified by a user (step 1). The protocol guides the user through the selection of an appropriate prediction system (step 2), the retrieval (step 3), pre-processing (step 4) and evaluation (step 5) of the data and how to resolve detected issues (step 6). A technical UNSEEN-open workflow for steps 3 to 5 is presented using ECMWF seasonal prediction system SEAS5 (Johnson et al., 2019). In this section, we discuss the practicalities of the UNSEEN-open workflow and other modelling systems that the same workflow could be applied to.

\subsection{Practicalities of the UNSEEN-open workflow}

In the UNSEEN-open workflow (steps 3 to 5 in Figure 1), SEAS5 monthly statistics are retrieved locally from the Copernicus Climate Data Store (Buontempo et al., 2020; Thepaut et al., 2018). SEAS5 has been used in other UNSEEN studies because it is a stable, homogeneous, global, high-resolution, large ensemble of weather variables (Hillier and Dixon, 2020; Kelder et al., 2020). The Copernicus Climate Data Store is chosen because the data are openly available and freely accessible and can be retrieved without intermediary. The case studies in this paper include monthly average statistics from CDS, but the workflow is sufficiently flexible to draw on monthly minimum or maximum data. For compound or multi-day events, daily data can be retrieved and processed to obtain the required metric.

At present, hindcast datasets are available for download and need to be pre-processed, which can be a timeconsuming process. An open workflow as presented in this paper would benefit from having large volumes of data such as the SEAS5 hindcast accessible on-demand via a cloud-based service (Pappenberger et al., 2021; Wagemann et al., 2018). An example of a cloud service for the meteorological and climate community, that in the future may be incorporated in the UNSEEN-open workflow to obviate retrieval of data, is the European Weather Cloud (Pappenberger and Palkovic, 2020). 


\subsection{Extension/application of the workflow to other datasets}

Ideally, the adequacy of the models should inform the selection of an appropriate prediction system (Step 2 and Figure 3). However, the availability of model simulations may be another important consideration. The UNSEENopen workflow was developed to generate and evaluate an UNSEEN ensemble from open access Copernicus SEAS5 simulations. The workflow is adjustable for other prediction systems (Table 3) but, here, retrieval was optimized for Copernicus SEAS5.

There are two points of attention for users to consider when using SEAS5: (1) the ensemble size depends on the selected block length and (2) the ensemble represents the conditions of the most recent decades only. Forecasts run for 6 months and, therefore, an ensemble size of 125 members can be created for monthly blocks, 75 members for seasonal blocks, and events longer than 5 consecutive months are not possible without stitching forecasts (section 2, step 3). When longer time periods are required to evaluate internal climate variability, century-long seasonal hindcasts with a similar set-up to SEAS5 but at lower resolution, such as the Coupled Seasonal Forecasts of the 20th Century (CSF-20C, Weisheimer et al., (2021)), or the Atmospheric Seasonal Forecasts of the 20th Century (ASF-20C, Weisheimer et al., (2017)) may be useful.

The UNSEEN approach has also been applied across a range of horizons, including medium/extended range, seasonal and decadal (Table 1). Medium-range predictions generally have a higher resolution than seasonal predictions (Set I-IV in Supplementary Table 1) but short time periods have mainly been used (e.g. Breivik et al., 2014, 2013; Meucci et al., 2018; Osinski et al., 2016). These studies use archived predictions, rather than retrospective hindcasts and short time periods ensure homogeneity because prediction systems within the archive are upgraded over time. Osinski et al. (2016) implemented a longer period ( 20 years as opposed to <10 years) by homogenising the data archive before generating a set of windstorms. Furthermore, UNSEEN can be applied to extended range or seasonal hydrological forecasts. For example, Brunner and Slater (2021) used the ensemble members from the European Flood Awareness System (EFAS, Arnal et al., 2018; Bartholmes et al., 2009; Smith et al., 2016) extended-range predictions to study unseen flood extremes across Europe.

Decadal predictions may equally be used to create a large ensemble. For instance, the Met Office decadal prediction system (DePreSys, Dunstone et al., 2016) has been used in several UNSEEN studies (e.g. Kay et al., 2020; Kent et al., 2019, 2017; Thompson et al., 2019, 2017). Users seeking to implement the UNSEEN-open workflow with this dataset may find DePreSys4 available via the Earth System Grid Federation (ESGF) as part of the Decadal Climate Prediction Project (DCPP). Furthermore, long series of UK weather events have been generated by stitching the 
weather@home system (Guillod et al., 2017; Massey et al., 2015) predictions for each year over 1900-2006 (Guillod et al., 2018).

Multi-decadal projections are less constrained to past conditions but can more readily be used to inform future risks of extreme events. Multi-decadal projections from Single Model Initial condition Large Ensembles, SMILEs (e.g. Deser et al., 2020) usually have a lower global resolution and therefore have been dynamically downscaled with regional climate models to produce high-resolution, large ensembles (Aalbers et al., 2018; Addor and Fischer, 2015; Huang et al., 2020). For example, Poschlod et al., (2021) downscaled a SMILE to calculate 10-year precipitation return values across Europe and Fischer et al., (2021) used a SMILE to estimate the likelihood of record-shattering heat events; van der Wiel et al., (2019) created a 2000-year streamflow large ensemble by forcing a global climate model into a global hydrological model; Gessner et al., (2021) boosted a large ensemble of heat wave events by perturbing SMILE simulations a few days to weeks before the event.

Most studies evaluating unprecedented extreme events have used single models to assess their magnitude and frequency. However, different model structures may simulate different extreme event magnitudes (e.g. van Kempen et al., 2021). Multi-model approaches have therefore been used in weather predictions, climate projections and event attribution studies (Palmer et al., 2005; Philip et al., 2020; Tebaldi and Knutti, 2007). Jain et al. (2020) were the first to apply a multi-model ensemble in an UNSEEN approach using the Climate-System Historical Forecast Project (Tompkins et al., 2017) to study extreme summer rainfall over India. The workflow presented in this paper can be extended to include all seasonal prediction systems available in the CDS. For users who do not want to retrieve data but wish to statistically emulate synthetic series, weather generators (Besombes et al., 2021; Beusch et al., 2020; Brunner and Gilleland, 2020; Wilks and Wilby, 1999) continue to be another option widely used in climate science (Alodah and Seidou, 2019; Kilsby et al., 2007; Perera et al., 2020; Semenov and Barrow, 1997). 
Table 3: Data sources for medium-range, seasonal and decadal prediction systems that have been used to study unseen extremes. Columns include their accessibility, spatial resolution, number of members in the ensemble, representative time window, and supporting references to UNSEEN analyses. A Table of all seasonal prediction systems available in the CDS is accessible at https://confluence.ecmwf.int/display/CKB/Summary+of+available+data.

\begin{tabular}{|c|c|c|c|c|c|c|}
\hline $\begin{array}{l}\text { Prediction } \\
\text { timescale }\end{array}$ & Data sources & $\begin{array}{l}\text { Open } \\
\text { access }\end{array}$ & $\begin{array}{l}\text { Spatial } \\
\text { resolution }\end{array}$ & $\begin{array}{l}\text { Number of } \\
\text { members }\end{array}$ & Time window & Supporting references \\
\hline $\begin{array}{l}\text { Medium- } \\
\text { range (10-15 } \\
\text { days) }\end{array}$ & ECMWF HRES and ENS & No & $\begin{array}{l}0.1^{\circ} \times 0.1^{\circ} \\
(\sim 12 \mathrm{~km})\end{array}$ & 51 & $1993-2010$ & $\begin{array}{l}\text { Breivik et al., 2014, 2013; Osinski et al., } \\
\text { 2016; Meucci et al., } 2018\end{array}$ \\
\hline $\begin{array}{l}\text { Extended- } \\
\text { range (22-46 } \\
\text { days) }\end{array}$ & $\begin{array}{l}\text { European Flood } \\
\text { Awareness System }\end{array}$ & Yes & $5 \mathrm{~km}$ & 10 & 1999-present & Brunner and Slater, 2021 \\
\hline $\begin{array}{l}\text { Seasonal (6 } \\
\text { months) }\end{array}$ & $\begin{array}{l}\text { ECMWF SEAS (MARS) } \\
\text { C3S seasonal predictions } \\
\text { The Climate-System } \\
\text { Historical Forecast } \\
\text { Project }\end{array}$ & $\begin{array}{l}\text { No } \\
\text { Yes } \\
\text { Yes }\end{array}$ & $\begin{array}{l}36 \mathrm{~km} \\
1^{\circ} \times 1^{\circ} \\
(\sim 110 \mathrm{~km}) \\
2.5^{\circ} \times 2.5^{\circ} \\
(\sim 275 \mathrm{~km})\end{array}$ & $\begin{array}{l}51 \\
10-40 \\
7-24\end{array}$ & $\begin{array}{l}\text { 1981-present } \\
\text { 1993-present } \\
\text { 1980-2012 }\end{array}$ & $\begin{array}{l}\text { van den Brink et al., 2005, 2004; Walz and } \\
\text { Leckebusch, 2019; Hillier and Dixon, 2020; } \\
\text { Kelder et al., } 2020 \\
\text { This study } \\
\text { Jain et al., } 2020\end{array}$ \\
\hline $\begin{array}{l}\text { Decadal }(1-10 \\
\text { years })\end{array}$ & $\begin{array}{l}\text { Met Office decadal } \\
\text { prediction system } \\
\text { (DePreSys3 / DePreSys4) } \\
\text { Weather@home }\end{array}$ & $\begin{array}{l}\text { No / } \\
\text { Yes } \\
\text { No }\end{array}$ & $\begin{array}{l}60 \mathrm{~km} \\
25 \mathrm{~km}\end{array}$ & $\begin{array}{l}40 / 10 \\
100\end{array}$ & $\begin{array}{r}1960-2020 \\
1900-2006\end{array}$ & $\begin{array}{l}\text { Thompson et al., 2019, 2017; Kent et al., } \\
\text { 2019, 2017; Kay et al., } 2020 \\
\text { Kay et al., 2018; Hall et al., 2020,2019 }\end{array}$ \\
\hline
\end{tabular}




\section{5. Summary and conclusion}

Hindcast ensembles from weather predictions have considerable potential for advancing understanding of climate risks. Estimates of rare extreme events or compound extremes can be improved through the large number of weather events that can be generated from these ensembles (Hillier and Dixon, 2020; Kelder et al., 2020; Thompson et al., 2017; van den Brink et al., 2004). To improve uptake and ensure rigour of these methods, we provide a protocol to

10 generate a credible, large ensemble of any type of hydro-climatic extreme. Our protocol is intended to guide and inform users about the wider applicability of UNSEEN, as well as to help with identifying and overcoming challenges associated with the method.

The applicability of UNSEEN is determined by multiple, interrelated factors. Ensemble member independence, model stability and model fidelity depend on the type of event being studied (the variable, spatial and temporal 15 extent, and geographical location), as well as on the prediction system applied. The prediction timescale furthermore influences the independence and stability, as longer simulations are more independent but have a higher chance of drifting away from climatology. Different systems, and the way they have been downscaled, initialized, and coupled, may yield different biases. Forecasting skill and associated biases may vary by region and season, influencing the independence, stability, and fidelity. Therefore, it is recommended that our protocol is used

20 to explore the applicability for the selected event definition and prediction system(s).

We used three case studies of extreme weather events in 2020 to illustrate the protocol. The UK February extreme precipitation event revealed an issue with the variability of the generated UNSEEN February precipitation events. This case study illustrates how the protocol may help understand the limitations of the approach and diagnose the lack of simulated precipitation variability in the underlying forecasting system.

25 In the case of Siberia, the 2020 March-May average temperature reached above zero degrees for the first time on record within ERA5, and this event was associated with major disruption, wildfires, and permafrost thawing (Ciavarella et al., 2021; Overland and Wang, 2021). A stress-test of thawing events over Siberia would have shown their plausibility within the UNSEEN ensemble before the event happened, for which the far-reaching impacts on permafrost peatlands were already widely known (e.g. Swindles et al., 2015). Such stress-tests of maximum

30 credible events, or, in other words, plausible yet unseen events are typically requested by policy makers (e.g. Swart et al., 2013; Wilby et al., 2011). UNSEEN is applicable to a wide range of sectors and end-users, who may benefit from stress-testing their systems with event-based storylines of plausible, yet unseen weather extremes (Matthews et al., 2016; Sillmann et al., 2021). For example, in the UK, UNSEEN has already successfully been deployed to 
inform decision making about unprecedented rainfall events (HM Government, 2016; Sillmann et al., 2021;

35 Thompson et al., 2017).

In the case of August 2020 temperatures during peak California wildfire activity, anomalies exceeded previous records by a considerable margin (Figure 2c,d). Such anomalous events can have large socio-economic consequences, especially when climate risk perception is driven by past experiences (Aerts et al., 2018; Weber, 2006). The UNSEEN approach reveals a strong trend in temperature extremes over the last 40 years, which has

40 increased the likelihood of events like the August 2020 temperature anomalies in the present climate (about $<1 \%$ in 2020), whilst it was virtually impossible in 1981. This trend is consistent with record-breaking or 'recordshattering' temperatures being expected to occur more frequently in a rapidly warming climate (Coumou et al., 2013; Fischer et al., 2021; Power and Delage, 2019). This case study shows how the UNSEEN-trends method (Kelder et al., 2020) may inform policies around adapting to the likelihood of present climate extremes rather than

45 past events. Seasonal and decadal predictions may furthermore contribute additional lines of evidence to attribution statements, as the changing frequency of extreme events can now be detected with greater confidence using the UNSEEN ensemble.

\section{Data and code availability}

All code to reproduce the work is available at https://github.com/esowc/UNSEEN-open and documentation is

50 available at https://unseen-open.readthedocs.io. The pre-processed data for the example case studies are available on the GitHub repository and the results can be reproduced at https://unseenopen.readthedocs.io/en/latest/Notebooks/Examples.html.

UNSEEN-open relies on the Copernicus Data Store (CDS) Python API (https://pypi.org/project/cdsapi/) for data retrieval; the Python xarray package (Hoyer and Hamman, 2017) for pre-processing; and uses R ggplot (Gómez-

55 Rubio, 2017) and extRemes (Gilleland et al., 2016) packages for evaluation, extreme value analysis and visualization. The evaluation tests have been developed into an 'UNSEEN' R-package (https://github.com/timokelder/UNSEEN). UNSEEN-open at present uses Copernicus SEAS5, ERA5 and EOBS datasets, which are openly available through the CDS (https://cds.climate.copernicus.eu/). The European Commission and ECMWF are not responsible for any use of UNSEEN-open. 
T.K. conceived and designed the study. T.K. developed the protocol with contributions from T.M., L.S., C.P., and R.W. T.K. developed the UNSEEN-open workflow with contributions from J.W. T.K. analysed the data and drafted the paper with input from all authors.

\section{Acknowledgements}

65 TK acknowledges support from Loughborough University and the NERC CENTA Doctoral Training Partnership, acknowledges computation facilities provided by the University of Oxford, and acknowledges support from the ECMWF Summer of Weather Code 2020 funded by Copernicus. ND acknowledges support from the Met Office Hadley Centre Climate Programme funded by BEIS. We acknowledge the EU-FP6 project UERRA (https://www.uerra.eu), data providers in the ECA\&D project (https://www.ecad.eu), and the Copernicus Climate

70 Change Service for the SEAS5, ERA5, and E-OBS datasets.

\section{References}

Aalbers, E.E., Lenderink, G., van Meijgaard, E., van den Hurk, B.J.J.M., 2018. Local-scale changes in mean and heavy precipitation in Western Europe, climate change or internal variability? Clim. Dyn. 50, 4745-4766. https://doi.org/10.1007/s00382-017-3901-9 in RCM simulations. J. Geophys. Res. Atmos. 120, 10180-10195. https://doi.org/10.1002/2014JD022824

Aerts, J.C.J.H., Botzen, W.J., Clarke, K.C., Cutter, S.L., Hall, J.W., Merz, B., Michel-Kerjan, E., Mysiak, J., Surminski, S., Kunreuther, H., 2018. Integrating human behaviour dynamics into flood disaster risk assessment. Nat. Clim. Chang. 8, 193-199. https://doi.org/10.1038/s41558-018-0085-1

80 Alexander, L. V, 2016. Global observed long-term changes in temperature and precipitation extremes: a review of progress and limitations in IPCC assessments and beyond. Weather Clim. Extrem. 11, 4-16. https://doi.org/https://doi.org/10.1016/j.wace.2015.10.007

Alley, R.B., Emanuel, K.A., Zhang, F., 2019. Advances in weather prediction. Science (80-. ). 363, 342-344. https://doi.org/10.1126/science.aav7274 
Alodah, A., Seidou, O., 2019. Assessment of Climate Change Impacts on Extreme High and Low Flows: An Improved Bottom-Up Approach. Water 11, 1236. https://doi.org/10.3390/w11061236

Arnal, L., Cloke, H.L., Stephens, E., Wetterhall, F., Prudhomme, C., Neumann, J., Krzeminski, B., Pappenberger, F., 2018. Skilful seasonal forecasts of streamflow over Europe? Hydrol. Earth Syst. Sci. 22, 2057-2072. https://doi.org/10.5194/hess-22-2057-2018

Bartholmes, J.C., Thielen, J., Ramos, M.H., Gentilini, S., 2009. The european flood alert system EFAS - Part 2: Statistical skill assessment of probabilistic and deterministic operational forecasts. Hydrol. Earth Syst. Sci. 13, 141-153. https://doi.org/10.5194/hess-13-141-2009

Bauer, P., Thorpe, A., Brunet, G., 2015. The quiet revolution of numerical weather prediction. Nature. https://doi.org/10.1038/nature14956

Bauer, T., Ingram, V., De Jong, W., Arts, B., 2018. The socio-economic impact of extreme precipitation and flooding on forest livelihoods: evidence from the Bolivian Amazon. Int. For. Rev. 20, 314-331. https://doi.org/10.1505/146554818824063050

Bellprat, O., Guemas, V., Doblas-Reyes, F., Donat, M.G., 2019. Towards reliable extreme weather and climate event attribution. Nat. Commun. 10, 1732. https://doi.org/10.1038/s41467-019-09729-2

100 Besombes, C., Pannekoucke, O., Lapeyre, C., Sanderson, B., Thual, O., 2021. Producing realistic climate data with GANs. Nonlinear Process. Geophys. Discuss. 1-39. https://doi.org/10.5194/npg-2021-6

Beusch, L., Gudmundsson, L., Seneviratne, S.I., 2020. Emulating Earth system model temperatures with MESMER: from global mean temperature trajectories to grid-point-level realizations on land. Earth Syst. Dyn. 11, 139-159. https://doi.org/10.5194/esd-11-139-2020

Bhatia, U., Ganguly, A.R., 2019. Precipitation extremes and depth-duration-frequency under internal climate variability. Sci. Rep. 9, 1-9. https://doi.org/10.1038/s41598-019-45673-3

Breivik, Ø., Aarnes, O.J., Abadalla, S., Bidlot, J.-R., Janssen, P., 2014. Wind and Wave Extremes over the World Oceans From Very Large Ensembles. Geophys. Res. Lett. 41, 5122-5131. https://doi.org/https://doi.org/10.1002/2014GL060997

110 Breivik, Ø., Aarnes, O.J., Bidlot, J.-R., Carrasco, A., Saetra, Ø., 2013. Wave Extremes in the Northeast Atlantic 
from Ensemble Forecasts. J. Clim. 26, 7525-7540. https://doi.org/https://doi.org/10.1175/JCLI-D-1200738.1

Brunner, M. 1., Slater, L., 2021. Extreme floods in Europe: going beyond observations using reforecast ensemble pooling. Hydrol. Earth Syst. Sci. Discuss. [preprint].

115 Brunner, M.I., Gilleland, E., 2020. Stochastic simulation of streamflow and spatial extremes: a continuous, waveletbased approach. Hydrol. Earth Syst. Sci. 24, 3967-3982. https://doi.org/10.5194/hess-24-3967-2020

Buontempo, C., Hutjes, R., Beavis, P., Berckmans, J., Cagnazzo, C., Vamborg, F., Thépaut, J.-N., Bergeron, C., Almond, S., Amici, A., Ramasamy, S., Dee, D., 2020. Fostering the development of climate services through Copernicus Climate Change Service (C3S) for agriculture applications. Weather Clim. Extrem. 27, 100226. https://doi.org/10.1016/j.wace.2019.100226

Cannon, A.J., Piani, C., Sippel, S., 2020. Bias correction of climate model output for impact models, in: Climate Extremes and Their Implications for Impact and Risk Assessment. Elsevier, pp. 77-104.

Casanueva, A., Herrera, S., Iturbide, M., Lange, S., Jury, M., Dosio, A., Maraun, D., Gutiérrez, J.M., 2020. Testing bias adjustment methods for regional climate change applications under observational uncertainty and resolution mismatch. Atmos. Sci. Lett. 21, e978. https://doi.org/10.1002/asl.978

Ciavarella, A., Cotterill, D., Stott, P., Kew, S., Philip, S., van Oldenborgh, G.J., Skålevåg, A., Lorenz, P., Robin, Y., Otto, F., Hauser, M., Seneviratne, S.I., Lehner, F., Zolina, O., 2021. Prolonged Siberian heat of 2020 almost impossible without human influence. Clim. Change 166, 9. https://doi.org/10.1007/s10584-02103052-w

130 Copernicus EMS, 2020. UK and Ireland floods, February 2020 | Copernicus EMS - European Flood Awareness System [WWW Document]. URL https://www.efas.eu/en/news/uk-and-ireland-floods-february-2020 (accessed 3.1.21).

Cornes, R.C., van der Schrier, G., van den Besselaar, E.J.M., Jones, P.D., 2018. An Ensemble Version of the EOBS Temperature and Precipitation Data Sets. J. Geophys. Res. Atmos. 123, 9391-9409. https://doi.org/10.1029/2017JD028200

Coumou, D., Robinson, A., Rahmstorf, S., 2013. Global increase in record-breaking monthly-mean temperatures. Clim. Change 118, 771-782. https://doi.org/10.1007/s10584-012-0668-1 
Courty, L.G., Wilby, R.L., Hillier, J.K., Slater, L.J., 2019. Intensity-duration-frequency curves at the global scale. Environ. Res. Lett. 14, 084045. https://doi.org/10.1088/1748-9326/ab370a

140 Covey, C., Gleckler, P.J., Phillips, T.J., Bader, D.C., 2006. Secular trends and climate drift in coupled oceanatmosphere general circulation models. J. Geophys. Res. 111, D03107. https://doi.org/10.1029/2005JD006009

Cowan, T., Undorf, S., Hegerl, G.C., Harrington, L.J., Otto, F.E.L., 2020. Present-day greenhouse gases could cause more frequent and longer Dust Bowl heatwaves. Nat. Clim. Chang. 10, 505-510. https://doi.org/10.1038/s41558-020-0771-7

Davies, P.A., McCarthy, M., Christidis, N., Dunstone, N., Fereday, D., Kendon, M., Knight, J.R., Scaife, A.A., Sexton, D., 2021. The wet and stormy $\langle\mathrm{scp}>\mathrm{UK}</ \mathrm{scp}>$ winter of 2019/2020. Weather 99, wea.3955. https://doi.org/10.1002/wea.3955

Deser, C., Lehner, F., Rodgers, K.B., Ault, T., Delworth, T.L., DiNezio, P.N., Fiore, A., Frankignoul, C., Fyfe, J.C., Horton, D.E., Kay, J.E., Knutti, R., Lovenduski, N.S., Marotzke, J., McKinnon, K.A., Minobe, S., Randerson, J., Screen, J.A., I.R., S., Ting, M., 2020. Insights from Earth system model initial-condition large ensembles and future prospects. Nat. Clim. Chang. in review.

Diffenbaugh, N.S., Singh, D., Mankin, J.S., Horton, D.E., Swain, D.L., Touma, D., Charland, A., Liu, Y., Haugen, M., Tsiang, M., Rajaratnam, B., 2017. Quantifying the influence of global warming on unprecedented extreme climate events. Proc. Natl. Acad. Sci. U. S. A. 114, 4881-4886. https://doi.org/10.1073/pnas.1618082114

Dunstone, N., Smith, D., Scaife, A., Hermanson, L., Eade, R., Robinson, N., Andrews, M., Knight, J., 2016. Skilful predictions of the winter North Atlantic Oscillation one year ahead. Nat. Geosci. 9, 809-814. https://doi.org/10.1038/ngeo2824

ECMWF, 2018. Climate reanalysis | ECMWF [WWW Document]. ECMWF. URL https://www.ecmwf.int/en/research/climate-reanalysis (accessed 3.23.21).

Eyring, V., Cox, P.M., Flato, G.M., Gleckler, P.J., Abramowitz, G., Caldwell, P., Collins, W.D., Gier, B.K., Hall, A.D., Hoffman, F.M., Hurtt, G.C., Jahn, A., Jones, C.D., Klein, S.A., Krasting, J.P., Kwiatkowski, L., Lorenz, R., Maloney, E., Meehl, G.A., Pendergrass, A.G., Pincus, R., Ruane, A.C., Russell, J.L., Sanderson, B.M., Santer, B.D., Sherwood, S.C., Simpson, I.R., Stouffer, R.J., Williamson, M.S., 2019. Taking climate model evaluation to the next level. Nat. Clim. Chang. 9, 102-110. https://doi.org/10.1038/s41558-018-0355-y 
Eyring, V., Righi, M., Lauer, A., Evaldsson, M., Wenzel, S., Jones, C., Anav, A., Andrews, O., Cionni, I., Davin, E.L., Deser, C., Ehbrecht, C., Friedlingstein, P., Gleckler, P., Gottschaldt, K.-D., Hagemann, S., Juckes, M., Kindermann, S., Krasting, J., Kunert, D., Levine, R., Loew, A., Mäkelä, J., Martin, G., Mason, E., Phillips, A.S., Read, S., Rio, C., Roehrig, R., Senftleben, D., Sterl, A., van Ulft, L.H., Walton, J., Wang, S., Williams, K.D., 2016. ESMValTool (v1.0) - a community diagnostic and performance metrics tool for routine evaluation of Earth system models in CMIP. Geosci. Model Dev. 9, 1747-1802. https://doi.org/10.5194/gmd9-1747-2016

Faranda, D., 2020. An attempt to explain recent changes in European snowfall extremes. Weather Clim. Dyn. 1, 445-458. https://doi.org/10.5194/wcd-1-445-2020

175 Fischer, E.M., Sippel, S., Knutti, R., 2021. Increasing probability of record-shattering climate extremes. Nat. Clim. Chang. 2021118 11, 689-695. https://doi.org/10.1038/s41558-021-01092-9

Flannigan, M., Cantin, A.S., De Groot, W.J., Wotton, M., Newbery, A., Gowman, L.M., 2013. Global wildland fire season severity in the 21st century. For. Ecol. Manage. 294, 54-61. https://doi.org/10.1016/j.foreco.2012.10.022

180 Gasparrini, A., Guo, Y., Hashizume, M., Lavigne, E., Zanobetti, A., Schwartz, J., Tobias, A., Tong, S., Rocklöv, J., Forsberg, B., Leone, M., De Sario, M., Bell, M.L., Guo, Y.-L.L., Wu, C., Kan, H., Yi, S.-M., de Sousa Zanotti Stagliorio Coelho, M., Saldiva, P.H.N., Honda, Y., Kim, H., Armstrong, B., 2015. Mortality risk attributable to high and low ambient temperature: a multicountry observational study. Lancet 386, 369-375. https://doi.org/10.1016/S0140-6736(14)62114-0

Geirinhas, J.L., Russo, A., Libonati, R., Sousa, P.M., Miralles, D.G., Trigo, R.M., 2021. Recent increasing frequency of compound summer drought and heatwaves in Southeast Brazil. Environ. Res. Lett. 16, 34036. https://doi.org/10.1088/1748-9326/abe0eb

Gessner, C., Fischer, E.M., Beyerle, U., Knutti, R., 2021. Very rare heat extremes: quantifying and understanding using ensemble re-initialization. J. Clim. 1-46. https://doi.org/10.1175/JCLI-D-20-0916.1

190 Gilleland, E., Katz, R.W., others, 2016. extRemes 2.0: an extreme value analysis package in R. J. Stat. Softw. 72, 1-39. https://doi.org/https://doi.org/10.18637/jss.v072.i08

Gómez-Rubio, V., 2017. ggplot2 - Elegant Graphics for Data Analysis (2nd Edition). J. Stat. Softw. 77. https://doi.org/10.18637/jss.v077.b02 
Goss, M., Swain, D.L., Abatzoglou, J.T., Sarhadi, A., Kolden, C.A., Williams, A.P., Diffenbaugh, N.S., 2020. Climate change is increasing the likelihood of extreme autumn wildfire conditions across California. Environ. Res. Lett. 15, 094016. https://doi.org/10.1088/1748-9326/ab83a7

Grazzini, F., Fragkoulidis, G., Pavan, V., Antolini, G., 2020. The 1994 Piedmont flood: an archetype of extreme precipitation events in Northern Italy. Bull. Atmos. Sci. Technol. 1, 283-295. https://doi.org/10.1007/s42865020-00018-1

Guillod, B.P., Jones, R.G., Bowery, A., Haustein, K., Massey, N.R., Mitchell, D.M., Otto, F.E.L., Sparrow, S.N., Uhe, P., Wallom, D.C.H., Wilson, S., Allen, M.R., 2017. Weather@home 2: Validation of an improved global-regional climate modelling system. Geosci. Model Dev. 10, 1849-1872. https://doi.org/10.5194/gmd10-1849-2017

Guillod, B.P., Jones, R.G., Dadson, S.J., Coxon, G., Bussi, G., Freer, J., Kay, A.L., Massey, N.R., Sparrow, S.N., Wallom, D.C.H., Allen, M.R., Hall, J.W., 2018. A large set of potential past, present and future hydrometeorological time series for the UK. Hydrol. Earth Syst. Sci. 22, 611-634. https://doi.org/10.5194/hess-22611-2018

Gupta, A. Sen, Jourdain, N.C., Brown, J.N., Monselesan, D., 2013. Climate drift in the CMIP5 models. J. Clim. 26, 8597-8615.

Gupta, A. Sen, Santoso, A., Taschetto, A.S., Ummenhofer, C.C., Trevena, J., England, M.H., 2009. Projected changes to the Southern Hemisphere ocean and sea ice in the IPCC AR4 climate models. J. Clim. 22, 30473078. https://doi.org/10.1175/2008JCLI2827.1

Hall, J.W., Borgomeo, E., Bruce, A., Di Mauro, M., Mortazavi-Naeini, M., 2019. Resilience of Water Resource Systems: Lessons from England. Water Secur. https://doi.org/10.1016/j.wasec.2019.100052

215 Hall, J.W., Mortazavi-Naeini, M., Borgomeo, E., Baker, B., Gavin, H., Gough, M., Harou, J.J., Hunt, D., Lambert, C., Piper, B., Richardson, N., Watts, G., 2020. Risk-based water resources planning in practice: a blueprint for the water industry in England. Water Environ. J. 34, 441-454. https://doi.org/10.1111/wej.12479

Hansen, J., Ruedy, R., Sato, M., Lo, K., 2010. Global surface temperature change. Rev. Geophys. 48, 4004. https://doi.org/10.1029/2010RG000345

220 Hardiman, S.C., Dunstone, N.J., Scaife, A.A., Smith, D.M., Knight, J.R., Davies, P., Claus, M., Greatbatch, R.J., 2020. Predictability of European winter 2019/20: Indian Ocean dipole impacts on the NAO. Atmos. Sci. Lett. 
21, e1005. https://doi.org/10.1002/ASL.1005

Hempel, S., Frieler, K., Warszawski, L., Schewe, J., Piontek, F., 2013. A trend-preserving bias correction - the ISIMIP approach. Earth Syst. Dyn. 4, 219-236. https://doi.org/10.5194/esd-4-219-2013

225 Hermanson, L., Ren, H.-L., Vellinga, M., Dunstone, N.D., Hyder, P., Ineson, S., Scaife, A.A., Smith, D.M., Thompson, V., Tian, B., Williams, K.D., 2018. Different types of drifts in two seasonal forecast systems and their dependence on ENSO. Clim. Dyn. 51, 1411-1426. https://doi.org/10.1007/s00382-017-3962-9

Hersbach, H., Bell, B., Berrisford, P., Hirahara, S., Horányi, A., Muñoz-Sabater, J., Nicolas, J., Peubey, C., Radu, R., Schepers, D., Simmons, A., Soci, C., Abdalla, S., Abellan, X., Balsamo, G., Bechtold, P., Biavati, G., Bidlot, J., Bonavita, M., De Chiara, G., Dahlgren, P., Dee, D., Diamantakis, M., Dragani, R., Flemming, J., Forbes, R., Fuentes, M., Geer, A., Haimberger, L., Healy, S., Hogan, R.J., Hólm, E., Janisková, M., Keeley, S., Laloyaux, P., Lopez, P., Lupu, C., Radnoti, G., de Rosnay, P., Rozum, I., Vamborg, F., Villaume, S., Thépaut, J.N., 2020. The ERA5 global reanalysis. Q. J. R. Meteorol. Soc. 146, 1999-2049. https://doi.org/10.1002/qj.3803

Hillier, J.K., Dixon, R.S., 2020. Seasonal impact-based mapping of compound hazards. Environ. Res. Lett. 15, 114013. https://doi.org/10.1088/1748-9326/abbc3d

HM Government, 2016. National Flood Resilience Review.

Hollis, D., McCarthy, M., Kendon, M., Legg, T., Simpson, I., 2019. HadUK-Grid-A new UK dataset of gridded climate observations. Geosci. Data J. 6, 151-159. https://doi.org/10.1002/GDJ3.78

Hoskins, B., 2013. The potential for skill across the range of the seamless weather-climate prediction problem: a stimulus for our science. Q. J. R. Meteorol. Soc. 139, 573-584. https://doi.org/10.1002/qj.1991

Hoyer, S., Hamman, J.J., 2017. xarray: N-D labeled Arrays and Datasets in Python. J. Open Res. Softw. 5. https://doi.org/10.5334/jors. 148

Huang, X., Swain, D.L., Hall, A.D., 2020. Future precipitation increase from very high resolution ensemble downscaling of extreme atmospheric river storms in California. Sci. Adv. 6, eaba1323. https://doi.org/10.1126/sciadv.aba1323

Jain, S., Scaife, A.A., Dunstone, N., Smith, D., Mishra, S.K., 2020. Current chance of unprecedented monsoon 
rainfall over India using dynamical ensemble simulations. Environ. Res. Lett. 15, 94095. https://doi.org/10.1088/1748-9326/ab7b98

250 Johnson, S.J., Stockdale, T.N., Ferranti, L., Balmaseda, M.A., Molteni, F., Magnusson, L., Tietsche, S., Decremer, D., Weisheimer, A., Balsamo, G., Keeley, S.P.E., Mogensen, K., Zuo, H., Monge-Sanz, B.M., 2019. SEAS5: the new ECMWF seasonal forecast system. Geosci. Model Dev. 12, 1087-1117. https://doi.org/10.5194/gmd12-1087-2019

Kay, A.L., Bell, V.A., Guillod, B.P., Jones, R.G., Rudd, A.C., 2018. National-scale analysis of low flow frequency: historical trends and potential future changes. Clim. Change 147, 585-599. https://doi.org/10.1007/s10584018-2145-y

Kay, G., Dunstone, N., Smith, D., Dunbar, T., Eade, R., Scaife, A., 2020. Current likelihood and dynamics of hot summers in the UK. Environ. Res. Lett. 15, 094099. https://doi.org/10.1088/1748-9326/abab32

Kelder, T., Müller, M., Slater, L.J., Marjoribanks, T.I., Wilby, R.L., Prudhomme, C., Bohlinger, P., Ferranti, L., Nipen, T., 2020. Using UNSEEN trends to detect decadal changes in 100-year precipitation extremes. npj Clim. Atmos. Sci. 3, 47. https://doi.org/10.1038/s41612-020-00149-4

Kennedy-Asser, A.T., Andrews, O., Mitchell, D.M., Warren, R.F., 2021. Evaluating heat extremes in the UK Climate Projections (UKCP18). Environ. Res. Lett. 16, 14039. https://doi.org/10.1088/1748-9326/abc4ad

Kent, C., Pope, E., Dunstone, N., Scaife, A.A., Tian, Z., Clark, R., Zhang, L., Davie, J., Lewis, K., 2019. Maize Drought Hazard in the Northeast Farming Region of China: Unprecedented Events in the Current Climate. J. Appl. Meteorol. Climatol. 58, 2247-2258. https://doi.org/10.1175/jamc-d-19-0096.1

Kent, C., Pope, E., Thompson, V., Lewis, K., Scaife, A.A., Dunstone, N., 2017. Using climate model simulations to assess the current climate risk to maize production. Environ. Res. Lett. 12, 054012. https://doi.org/10.1088/1748-9326/aa6cb9

270 Kilsby, C.G., Jones, P.D., Burton, A., Ford, A.C., Fowler, H.J., Harpham, C., James, P., Smith, A., Wilby, R.L., 2007. A daily weather generator for use in climate change studies. Environ. Model. Softw. 22, 1705-1719.

Kim, D.-I., Han, D., Lee, T., 2021. Reanalysis Product-Based Nonstationary Frequency Analysis for Estimating Extreme Design Rainfall. Atmosphere (Basel). 12, 191. https://doi.org/10.3390/atmos12020191 
King, A.D., Karoly, D.J., Henley, B.J., 2017. Australian climate extremes at $1.5^{\circ} \mathrm{c}$ and $2{ }^{\circ} \mathrm{c}$ of global warming. Nat. Clim. Chang. 7, 412-416. https://doi.org/10.1038/nclimate3296

Kirchmeier-Young, M.C., Zhang, X., 2020. Human influence has intensified extreme precipitation in North America. Proc. Natl. Acad. Sci. U. S. A. 117, 13308-13313. https://doi.org/10.1073/pnas.1921628117

Klomp, J., Valckx, K., 2014. Natural disasters and economic growth: A meta-analysis. Glob. Environ. Chang. 26, 183-195. https://doi.org/10.1016/j.gloenvcha.2014.02.006

Lange, S., 2019. Trend-preserving bias adjustment and statistical downscaling with ISIMIP3BASD (v1.0). Geosci. Model Dev. 12, 3055-3070. https://doi.org/10.5194/gmd-12-3055-2019

Lavers, D.A., Pappenberger, F., Zsoter, E., 2014. Extending medium-range predictability of extreme hydrological events in Europe. Nat. Commun. 5, 5382. https://doi.org/https://doi.org/10.1038/ncomms6382

Lehner, F., Coats, S., Stocker, T.F., Pendergrass, A.G., Sanderson, B.M., Raible, C.C., Smerdon, J.E., 2017. Projected drought risk in $1.5^{\circ} \mathrm{C}$ and $2^{\circ} \mathrm{C}$ warmer climates. Geophys. Res. Lett. 44, 7419-7428. https://doi.org/10.1002/2017GL074117

Liepert, B.G., Previdi, M., 2012. Inter-model variability and biases of the global water cycle in CMIP3 coupled climate models. Environ. Res. Lett. 7, 12. https://doi.org/10.1088/1748-9326/7/1/014006

Lorenz, E.N., 1963. Deterministic nonperiodic flow. J. Atmos. Sci. 20, 130-141.

Lucarini, V., Ragone, F., 2011. ENERGETICS OF CLIMATE MODELS: NET ENERGY BALANCE AND MERIDIONAL ENTHALPY TRANSPORT. Rev. Geophys. 49, RG1001. https://doi.org/10.1029/2009RG000323

Maraun, D., Widmann, M., 2018. Statistical Downscaling and Bias Correction for Climate Research. Cambridge University Press. https://doi.org/10.1017/9781107588783

295 Massey, N., Jones, R., Otto, F.E.L., Aina, T., Wilson, S., Murphy, J.M., Hassell, D., Yamazaki, Y.H., Allen, M.R., 2015. weather@home-development and validation of a very large ensemble modelling system for probabilistic event attribution. Q. J. R. Meteorol. Soc. 141, 1528-1545. https://doi.org/10.1002/qj.2455 
Matthews, T., Mullan, D., Wilby, R.L., Broderick, C., Murphy, C., 2016. Past and future climate change in the context of memorable seasonal extremes. Clim. Risk Manag. 11, 37-52. https://doi.org/10.1016/j.crm.2016.01.004

Meucci, A., Young, I.R., Breivik, Ø., 2018. Wind and Wave Extremes from Atmosphere and Wave Model Ensembles. J. Clim. 31, 8819-8842. https://doi.org/https://doi.org/10.1175/JCLI-D-18-0217.1

Miralles, D.G., Gentine, P., Seneviratne, S.I., Teuling, A.J., 2019. Land-atmospheric feedbacks during droughts and heatwaves: state of the science and current challenges. Ann. N. Y. Acad. Sci. 1436, $19-35$. https://doi.org/10.1111/nyas.13912

Mitchell, D., AchutaRao, K., Allen, M., Bethke, I., Beyerle, U., Ciavarella, A., Forster, P.M., Fuglestvedt, J., Gillett, N., Haustein, K., Ingram, W., Iversen, T., Kharin, V., Klingaman, N., Massey, N., Fischer, E., Schleussner, C.-F., Scinocca, J., Seland, Ø., Shiogama, H., Shuckburgh, E., Sparrow, S., Stone, D., Uhe, P., Wallom, D., Wehner, M., Zaaboul, R., 2017. Half a degree additional warming, prognosis and projected impacts (HAPPI): background and experimental design. Geosci. Model Dev. 10, 571-583. https://doi.org/10.5194/gmd-10-571-2017

Moore, P., Hannah, B., de Vries, J., Poortvliet, M., Steffens, R., Stoof, C.R., 2020. Wildland fire management under COVID-19. Brief 1, review of materials. Wageningen University. https://doi.org/10.18174/521344

Osinski, R., Lorenz, P., Kruschke, T., Voigt, M., Ulbrich, U., Leckebusch, G.C., Faust, E., Hofherr, T., Majewski, D., 2016. An approach to build an event set of European windstorms based on ECMWF EPS. Nat. Hazards Earth Syst. Sci. 16, 255-268. https://doi.org/10.5194/nhess-16-255-2016

Overland, J.E., Wang, M., 2021. The 2020 Siberian heat wave. Int. J. Climatol. 41. https://doi.org/10.1002/joc.6850

Palmer, T.., Doblas-Reyes, F.., Hagedorn, R., Weisheimer, A., 2005. Probabilistic prediction of climate using multi-model ensembles: from basics to applications. Philos. Trans. R. Soc. B Biol. Sci. 360, 1991-1998. https://doi.org/10.1098/RSTB.2005.1750

Palmer, T., 2019. The ECMWF ensemble prediction system: Looking back (more than) 25 years and projecting forward 25 years. Q. J. R. Meteorol. Soc. 145, 12-24. https://doi.org/10.1002/qj.3383

Palmer, T.N., Weisheimer, A., 2018. A Simple Pedagogical Model Linking Initial-Value Reliability with Trustworthiness in the Forced Climate Response. Bull. Am. Meteorol. Soc. 99, 605-614. https://doi.org/10.1175/BAMS-D-16-0240.1 
Pappenberger, F., Palkovic, M., 2020. Progress towards a European Weather Cloud | ECMWF [WWW Document]. ECMWF Newsl. https://doi.org/10.21957/9pft4uy055

Pappenberger, F., Rabier, F., Venuti, F., 2021. Invited perspectives: The ECMWF strategy 2021--2030 Challenges in the area of natural hazards. Nat. Hazards Earth Syst. Sci. Discuss. 2021, 1-6. https://doi.org/10.5194/nhess2021-33

Parker, W.S., 2016. Reanalyses and observations: What's the difference? Bull. Am. Meteorol. Soc. 97, 1565-1572. https://doi.org/https://doi.org/10.1175/BAMS-D-14-00226.1

Pascale, S., Kapnick, S.B., Delworth, T.L., Cooke, W.F., 2020. Increasing risk of another Cape Town "day Zero" drought in the 21st century. Proc. Natl. Acad. Sci. U. S. A. https://doi.org/10.1073/pnas.2009144117

Perera, A.T.D., Nik, V.M., Chen, D., Scartezzini, J.L., Hong, T., 2020. Quantifying the impacts of climate change and extreme climate events on energy systems. Nat. Energy 5, 150-159. https://doi.org/10.1038/s41560-0200558-0

Perry, M., Hollis, D., 2005. The generation of monthly gridded datasets for a range of climatic variables over the UK. Int. J. Climatol. 25, 1041-1054. https://doi.org/10.1002/joc.1161

Philip, S., Kew, S., van Oldenborgh, G.J., Otto, F., Vautard, R., van der Wiel, K., King, A., Lott, F., Arrighi, J., Singh, R., van Aalst, M., 2020. A protocol for probabilistic extreme event attribution analyses. Adv. Stat. Climatol. Meteorol. Oceanogr. 6, 177-203. https://doi.org/10.5194/ascmo-6-177-2020

Pickrell, J., Pennisi, E., 2020. Record U.S. and Australian fires raise fears for many species. Science (80-. ). 370, 18-19. https://doi.org/10.1126/science.370.6512.18

345 Poschlod, B., Ludwig, R., Sillmann, J., 2021. Ten-year return levels of sub-daily extreme precipitation over Europe. Earth Syst. Sci. Data 13, 983-1003. https://doi.org/10.5194/essd-13-983-2021

Power, S.B., Delage, F.P.D., 2019. Setting and smashing extreme temperature records over the coming century. Nat. Clim. Chang. 201997 9, 529-534. https://doi.org/10.1038/s41558-019-0498-5

Rahmstorf, S., 1995. Climate drift in an ocean model coupled to a simple, perfectly matched atmosphere. Clim. Dyn. 11, 447-458. https://doi.org/10.1007/BF00207194 
Salas, J.D., Obeysekera, J., Vogel, R.M., 2018. Techniques for assessing water infrastructure for nonstationary extreme events: a review. Hydrol. Sci. J. 63, 325-352. https://doi.org/10.1080/02626667.2018.1426858

Semenov, M.A., Barrow, E.M., 1997. Use of a stochastic weather generator in the development of climate change scenarios. Clim. Change 35, 397-414.

Sillmann, J., Shepherd, T.G., van den Hurk, B., Hazeleger, W., Martius, O., Slingo, J., Zscheischler, J., 2021. Event-Based Storylines to Address Climate Risk. Earth's Futur. 9, e2020EF001783. https://doi.org/10.1029/2020EF001783

Sillmann, J., Thorarinsdottir, T., Keenlyside, N., Schaller, N., Alexander, L. V., Hegerl, G., Seneviratne, S.I., Vautard, R., Zhang, X., Zwiers, F.W., 2017. Understanding, modeling and predicting weather and climate extremes: Challenges and opportunities. Weather Clim. Extrem. https://doi.org/10.1016/j.wace.2017.10.003

Slater, L.J., Anderson, B., Buechel, M., Dadson, S., Han, S., Harrigan, S., Kelder, T., Kowal, K., Lees, T., Matthews, T., Murphy, C., Wilby, R.L., 2021. Nonstationary weather and water extremes: a review of methods for their detection, attribution, and management. Hydrol. Earth Syst. Sci. 25, 3897-3935. https://doi.org/10.5194/hess-25-3897-2021

Smith, P.J., Pappenberger, F., Wetterhall, F., Thielen Del Pozo, J., Krzeminski, B., Salamon, P., Muraro, D., Kalas, M., Baugh, C., 2016. On the Operational Implementation of the European Flood Awareness System (EFAS), in: Flood Forecasting: A Global Perspective. Elsevier Inc., pp. 313-348. https://doi.org/10.1016/B978-0-12801884-2.00011-6

Stevenson, S., Timmermann, A., Chikamoto, Y., Langford, S., DiNezio, P., 2015. Stochastically Generated North American Megadroughts. J. Clim. 28, 1865-1880. https://doi.org/10.1175/JCLI-D-13-00689.1

Suarez-Gutierrez, L., Milinski, S., Maher, N., 2021. Exploiting large ensembles for a better yet simpler climate model evaluation. Clim. Dyn. 1, 3. https://doi.org/10.1007/s00382-021-05821-w

Suarez-Gutierrez, L., Müller, W.A., Li, C., Marotzke, J., 2020. Dynamical and thermodynamical drivers of variability in European summer heat extremes. Clim. Dyn. 54, 4351-4366. https://doi.org/10.1007/s00382020-05233-2

Swain, D.L., Wing, O.E.J., Bates, P.D., Done, J.M., Johnson, K.A., Cameron, D.R., 2020. Increased Flood Exposure Due to Climate Change and Population Growth in the United States. Earth's Futur. 8, e2020EF001778. https://doi.org/10.1029/2020EF001778 
Swart, R., Fuss, S., Obersteiner, M., Ruti, P., Teichmann, C., Vautard, R., 2013. Beyond vulnerability assessment. Nat. Clim. Chang. 2013 311 3, 942-943. https://doi.org/10.1038/nclimate2029

Swindles, G.T., Morris, P.J., Mullan, D., Watson, E.J., Turner, T.E., Roland, T.P., Amesbury, M.J., Kokfelt, U., Schoning, K., Pratte, S., Gallego-Sala, A., Charman, D.J., Sanderson, N., Garneau, M., Carrivick, J.L., Woulds, C., Holden, J., Parry, L., Galloway, J.M., 2015. The long-term fate of permafrost peatlands under rapid climate warming. Sci. Reports 201551 5, 1-6. https://doi.org/10.1038/srep17951

385 Tebaldi, C., Knutti, R., 2007. The use of the multi-model ensemble in probabilistic climate projections. Philos. Trans. R. Soc. A Math. Phys. Eng. Sci. 365, 2053-2075.

Thepaut, J.-N., Dee, D., Engelen, R., Pinty, B., 2018. The Copernicus Programme and its Climate Change Service, in: IGARSS 2018 - 2018 IEEE International Geoscience and Remote Sensing Symposium. IEEE, pp. 15911593. https://doi.org/10.1109/IGARSS.2018.8518067

Thompson, V., Dunstone, N.J., Scaife, A.A., Smith, D.M., Hardiman, S.C., Ren, H.-L., Lu, B., Belcher, S.E., 2019. Risk and dynamics of unprecedented hot months in South East China. Clim. Dyn. 52, 2585-2596. https://doi.org/10.1007/s00382-018-4281-5

Thompson, V., Dunstone, N.J., Scaife, A.A., Smith, D.M., Slingo, J.M., Brown, S., Belcher, S.E., 2017. High risk of unprecedented UK rainfall in the current climate. Nat. Commun. 8, 107.

Tompkins, A.M., De Záratate, M.I.O., Saurral, R.I., Vera, C., Saulo, C., Merryfield, W.J., Sigmond, M., Lee, W.S., Baehr, J., Braun, A., Butler, A., Déqué, M., Doblas-Reyes, F.J., Gordon, M., Scacaife, A.A., Imada, Y., Ishii, M., Ose, T., Kirtmatmatman, B., Kumar, A., Müller, W.A., Pirani, A., Stockdale, T., Rixen, M., Yasuda, T., 2017. The climate-system historical forecast project: Providing open access to seasonal forecast ensembles from centers around the globe. Bull. Am. Meteorol. Soc. 98, 2293-2301. https://doi.org/10.1175/BAMS-D16-0209.1

UK Met Office, 2020. Record breaking rainfall [WWW Document]. URL https://www.metoffice.gov.uk/aboutus/press-office/news/weather-and-climate/2020/2020-winter-february-stats (accessed 3.11.21).

van den Brink, H.W., Können, G.P., Opsteegh, J.D., van Oldenborgh, G.J., Burgers, G., 2005. Estimating return periods of extreme events from ECMWF seasonal forecast ensembles. Int. J. Climatol. 25, 1345-1354. https://doi.org/10.1002/joc.1155

van den Brink, H.W., Können, G.P., Opsteegh, J.D., van Oldenborgh, G.J., Burgers, G., 2004. Improving 104 - 
year surge level estimates using data of the ECMWF seasonal prediction system. Geophys. Res. Lett. 31, L17210. https://doi.org/10.1029/2004GL020610

van der Wiel, K., Kapnick, S.B., van Oldenborgh, G.J., Whan, K., Philip, S., Vecchi, G.A., Singh, R.K., Arrighi, J., Cullen, H., 2017. Rapid attribution of the August 2016 flood-inducing extreme precipitation in south Louisiana to climate change. Hydrol. Earth Syst. Sci. 21, 897-921. https://doi.org/10.5194/hess-21-897-2017

van der Wiel, K., Kapnick, S.B., Vecchi, G.A., Smith, J.A., Milly, P.C.D., Jia, L., 2018. 100-Year Lower Mississippi Floods in a Global Climate Model: Characteristics and Future Changes. J. Hydrometeorol. 19, 1547-1563. https://doi.org/10.1175/JHM-D-18-0018.1

van der Wiel, K., Selten, F.M., Bintanja, R., Blackport, R., Screen, J.A., 2020. Ensemble climate-impact modelling: extreme impacts from moderate meteorological conditions. Environ. Res. Lett. 15, 34050. https://doi.org/10.1088/1748-9326/ab7668

van der Wiel, K., Wanders, N., Selten, F.M., Bierkens, M.F.P., 2019. Added Value of Large Ensemble Simulations for Assessing Extreme River Discharge in a $2{ }^{\circ} \mathrm{C}$ Warmer World. Geophys. Res. Lett. 46, 2093-2102. https://doi.org/https://doi.org/10.1029/2019GL081967

van Kempen, G., van der Wiel, K., Melsen, L.A., 2021. The impact of hydrological model structure on the simulation of extreme runoff events. Nat. Hazards Earth Syst. Sci. 21, 961-976. https://doi.org/10.5194/nhess-21-961-2021

van Oldenborgh, G.J., van der Wiel, K., Kew, S., Philip, S., Otto, F., Vautard, R., King, A., Lott, F., Arrighi, J., Singh, R., van Aalst, M., 2021. Pathways and pitfalls in extreme event attribution. Clim. Change 166, 13. https://doi.org/10.1007/s10584-021-03071-7

Vautard, R., Christidis, N., Ciavarella, A., Alvarez-Castro, C., Bellprat, O., Christiansen, B., Colfescu, I., Cowan, T., Doblas-Reyes, F., Eden, J., Hauser, M., Hegerl, G., Hempelmann, N., Klehmet, K., Lott, F., Nangini, C., Orth, R., Radanovics, S., Seneviratne, S.I., van Oldenborgh, G.J., Stott, P., Tett, S., Wilcox, L., Yiou, P., 2019. Evaluation of the HadGEM3-A simulations in view of detection and attribution of human influence on extreme events in Europe. Clim. Dyn. 52, 1187-1210. https://doi.org/10.1007/s00382-018-4183-6

Vitolo, C., Di Giuseppe, F., Barnard, C., Coughlan, R., San-Miguel-Ayanz, J., Libertá, G., Krzeminski, B., 2020. ERA5-based global meteorological wildfire danger maps. Sci. Data 7, 1-11. https://doi.org/10.1038/s41597020-0554-Z 
435 Wagemann, J., Clements, O., Marco Figuera, R., Rossi, A.P., Mantovani, S., 2018. Geospatial web services pave new ways for server-based on-demand access and processing of Big Earth Data. Int. J. Digit. Earth 11, 7-25. https://doi.org/10.1080/17538947.2017.1351583

Walz, M.A., Leckebusch, G.C., 2019. Loss potentials based on an ensemble forecast: How likely are winter windstorm losses similar to 1990? Atmos. Sci. Lett. 20, e891. https://doi.org/10.1002/asl.891

440 Warszawski, L., Frieler, K., Huber, V., Piontek, F., Serdeczny, O., Schewe, J., 2014. The Inter-Sectoral Impact Model Intercomparison Project (ISI-MIP): Project framework. Proc. Natl. Acad. Sci. 111, 3228-3232. https://doi.org/10.1073/pnas.1312330110

Weber, E.U., 2006. Experience-Based and Description-Based Perceptions of Long-Term Risk: Why Global Warming does not Scare us (Yet). Clim. Chang. 2006 771 77, 103-120. https://doi.org/10.1007/S10584-0069060-3

Wehner, M., Gleckler, P., Lee, J., 2020. Characterization of long period return values of extreme daily temperature and precipitation in the CMIP6 models: Part 1, model evaluation. Weather Clim. Extrem. 30, 100283. https://doi.org/10.1016/j.wace.2020.100283

Weigel, K., Bock, L., Gier, B.K., Lauer, A., Righi, M., Schlund, M., Adeniyi, K., Andela, B., Arnone, E., Berg, P., Caron, L.-P., Cionni, I., Corti, S., Drost, N., Hunter, A., Lledó, L., Mohr, C.W., Paçal, A., Pérez-Zanón, N., Predoi, V., Sandstad, M., Sillmann, J., Sterl, A., Vegas-Regidor, J., von Hardenberg, J., Eyring, V., 2021. Earth System Model Evaluation Tool (ESMValTool) v2.0 - diagnostics for extreme events, regional and impact evaluation, and analysis of Earth system models in CMIP. Geosci. Model Dev. 14, 3159-3184. https://doi.org/10.5194/gmd-14-3159-2021

Weisheimer, A., Befort, D.J., MacLeod, D., Palmer, T., O’Reilly, C., Strømmen, K., 2021. Seasonal forecasts of the twentieth century. Bull. Am. Meteorol. Soc. https://doi.org/10.1175/BAMS-D-19-0019.1

Weisheimer, A., Decremer, D., MacLeod, D., O’Reilly, C., Stockdale, T.N., Johnson, S., Palmer, T.N., 2019. How confident are predictability estimates of the winter North Atlantic Oscillation? Q. J. R. Meteorol. Soc. 145, 140-159. https://doi.org/10.1002/qj.3446

460 Weisheimer, A., Palmer, T.N., 2014. On the reliability of seasonal climate forecasts. J. R. Soc. Interface 11, 20131162. https://doi.org/10.1098/rsif.2013.1162

Weisheimer, A., Schaller, N., O’Reilly, C., MacLeod, D.A., Palmer, T., 2017. Atmospheric seasonal forecasts of 
the twentieth century: multi-decadal variability in predictive skill of the winter North Atlantic Oscillation (NAO) and their potential value for extreme event attribution. Q. J. R. Meteorol. Soc. 143, 917-926. https://doi.org/10.1002/qj.2976

Wilby, R.L., Clifford, N.J., De Luca, P., Harrigan, S., Hillier, J.K., Hodgkins, R., Johnson, M.F., Matthews, T.K.R., Murphy, C., Noone, S.J., others, 2017. The 'dirty dozen'of freshwater science: detecting then reconciling hydrological data biases and errors. Wiley Interdiscip. Rev. Water 4, e1209. https://doi.org/https://doi.org/10.1002/wat2.1209

470 Wilby, R.L., Nicholls, R.J., Warren, R., Wheater, H.S., Clarke, D., Dawson, R.J., 2011. Keeping nuclear and other coastal sites safe from climate change. Proc. Inst. Civ. Eng. Civ. Eng. https://doi.org/10.1680/cien.2011.164.3.129

Wilks, D.S., 2011. Statistical methods in the atmospheric sciences. Academic press.

Wilks, D.S., Wilby, R.L., 1999. The weather generation game: a review of stochastic weather models. Prog. Phys. Geogr. Earth Environ. 23, 329-357. https://doi.org/10.1177/030913339902300302

Zadra, A., Williams, K., Frassoni, A., Rixen, M., Adames, Á.F., Berner, J., Bouyssel, F., Casati, B.B., Christensen, H., Ek, M.B., Flato, G., Huang, Y., Judt, F.K., Lin, H., Maloney, E., Merryfield, W., Van Niekerk, A., Rackow, T., Saito, K.Z., Wedi, N., Yadav, P.K., 2018. Systematic errors in weather and climate models: Nature, origins, and ways forward, in: Bulletin of the American Meteorological Society. American Meteorological Society, pp. ES67-ES70. https://doi.org/10.1175/BAMS-D-17-0287.1 